\title{
Pronominal Typology \& the de se/de re distinction
}

\author{
Pritty Patel-Grosz (University of Oslo)
}

Accepted by Linguistics \& Philosophy June 2019

\section{Introduction}

This paper investigates how regular pronominal typology (e.g., clitic vs. non-clitic pronouns) interfaces with de se and de re interpretations; it highlights a correlation between strong pronouns (descriptively speaking) and (non-de se) de re interpretations, and between weak pronouns and de se interpretations. In order to illustrate this correlation, I contrast different pronominal forms within a single language, null vs. overt pronouns in Kutchi Gujarati, and clitic vs. full pronouns in Austrian Bavarian. I argue, as outlined in the remainder of this paragraph, that the data presented here provide cross-linguistic comparative support for a view where de se pronouns have a special status, as in the dedicated de se LFs of Percus \& Sauerland (2003a,b). The empirical findings in this paper reveal a new observation regarding pronominal typology, namely that stronger pronouns resist a de se construal. Contrastively, the "weaker" a pronoun is (in comparison to other pronouns within the same language), the more likely it is to be interpreted de se. To analyse this, I propose that pronominal strength correlates with structural complexity (in terms of Cardinaletti \& Starke 1999), i.e. overt pronouns have more syntactic structure than null pronouns; similarly, non-clitic pronouns have more structure than clitic pronouns. The correlation between de se readings and weakness can be derived from an analysis in the spirit of Percus \& Sauerland (2003a,b), which assumes that de se pronouns are uninterpreted and merely serve to trigger predicate abstraction. Stronger pronouns, which have more structure, can be taken to simply resist being uninterpreted, given that structural economy constraints (such as Minimize DP! from Patel-Grosz \& Grosz 2017:279) require the most minimal pronoun unless a less minimal variant is independently required. Conversely, the observation that weak pronouns exhibit a preference for a de se reading can be argued to follow in the pragmatics from their competition with strong pronouns; since strong pronouns cannot generally be read de se, they will be identified as the prototypical (non-de se) de re pronouns, whereas weak pronouns, which can be read de se, will be dispreferred in a (non-de se) de re use.

To state the overarching goal of this paper from a bird's eye perspective, I develop a novel approach to the connection between the morphosyntax and meaning of pronouns in the complements of attitude verbs, argueing that the semantics of pronouns in such contexts is strongly interlinked with their internal structure (i.e., how much functional material they project).

Zooming in, the structure of this paper is as follows. I start with a brief discussion of the theoretical background on the de se vs. de re distinction (section 2) and the debates that emerge from it, in order to situate it in the broader context. The main contribution of my paper (as presented in section 3) to our understanding of de se vs. de re readings (based on an approach to pronominal typology that I outline in section 3.1) is threefold and can be outlined as follows.

First, I look at dream reports (Percus \& Sauerland 2003b) and demonstrate (in section 3.2) a cross-linguistic correlation between pronominal deficiency (in the sense that clitic or null pronouns are more deficient than non-clitic overt pronouns) and pronominal reference. Specifically, we find that only the most reduced forms in a given language (e.g., clitic pronouns) can refer to the 'dream self', while such reference is impossible for the less reduced forms (i.e., non-clitic pronouns). Such reference is typically viewed as a type of de se reference. The 
observed correlation is reminiscent of what we find with expletives and 'weather it', which are generally assumed to be semantically vacuous; it thus supports a view (such as Percus \& Sauerland's) in which de se pronouns are uninterpreted and give rise to a dedicated de se LF.

Second, while the observed correlation seems weaker with belief reports (than with dream reports), it still holds, as shown in section 3.3. This further corroborates my conclusion from dream reports that militates in favor of dedicated de se LFs and 'uninterpreted de se pronouns'; it thus supports a compositional analysis of belief reports in line with Chierchia (1989) and Percus \& Sauerland (2003a).

Third, we can shed light on the correlation between pronominal deficiency and pronominal function by considering hierarchies of pronominal strength that can be independently established. I show this throughout sections 3.1, 3.2 and 3.3; I model such hierarchies (e.g., clitic personal pronoun $<$ full personal pronoun $<$ demonstrative pronoun) in terms of a structural asymmetry, i.e. the 'stronger' pronouns (which are ranked higher) have more structure than the 'weaker' pronouns (which are ranked lower). In general, dedicated de se pronouns, which I treat as semantically uninterpreted, must be the hierarchically lowest pronouns for two reasons (see, in particular, section 3.1.3): [i.] structural economy constraints block the use of stronger pronouns when it is not independently licensed; and/or [ii.] additional functional heads in a pronoun's structure may have semantic interpretation of their own.

\section{The overarching debate: how to analyse de se vs. de re pronouns}

\subsection{Introducing de se vs. de re pronouns}

Pronouns under attitude verbs (such as believe, Percus \& Sauerland 2003a, and dream, Percus \& Sauerland 2003b) allow for two readings when they are referentially connected to the attitude holder (i.e. the believer or dreamer) (see Lewis 1979, Perry 1979), as shown in (1). (1a) illustrates the de se reading, which conveys a self-directed belief; contrastively, (1b) shows the (non-de se) ${ }^{1}$ de re reading, which conveys an 'unaware' belief directed towards the believer in the actual world. The crucial aspect of the (non-de se) de re reading is the lack of self-awareness, i.e. in (1b), John does not have a belief that he could describe by using a first person pronoun; such contexts are often subsumed under the notion of mistaken identity contexts.

(1) a. de se context: John looks at himself in the mirror and thinks: "I am tall."

John believes that he $\mathbf{d e}_{\mathrm{de}}$ is tall.

b. (non-de se) de re context: John watches a video of himself playing soccer, not recognizing himself and thinks: "That man in the video is tall."

John believes that he $\mathbf{e}_{\text {de re }}$ is tall.

At various points in the literature, it has been argued that the distinction between the de se reading in (1a) and the (non-de se) de re reading in (1b) has grammatical implications; for instance, there are special elements such as the PRO of control constructions (e.g. Chierchia 1989), and so called logophoric pronouns (e.g. Schlenker 2003), which have been claimed to only allow for de se readings, which seems to be a grammatical property of such elements. The aim of this paper is to shed new light on the nature of the referential dependencies in (1a) and (1b), i.e. on the syntax and semantics that gives rise to de se and (non-de se) de re readings.

\footnotetext{
${ }^{1}$ This qualification, which I will omit in later parts of the paper, is explained in section 2.2.
} 
On a terminological note, I will also use the same labels (i.e. de se and (non-de se) de re) when talking about dream reports in which the attitude holder dreams to be someone else. For now, suffice it to say that a de se reading picks out the 'dream self' (which may be, somewhat counter-intuitively, distinct from the actual dreamer), as in (2a), whereas a (non-de se) de re reading can pick out the dreamer, $(2 \mathrm{~b})$. The logic behind this will become clearer in section 2.2 .

(2) John dreams to be Bill, and he dreams of a soccer match that Bill and John are a part of.

a. de se context: In this dream, Bill just scored a goal.

John dreams that he $\mathbf{e}_{\text {de se }}(=$ Bill / the dream self) just scored a goal.

b. (non-de se) de re context: In this dream, John just scored a goal.

John dreams that he de re $(=\mathbf{J o h n} /$ the actual dreamer $)$ just scored a goal.

Of course, there are also clear differences between belief reports and dream reports, as follows. In belief reports, a de se reading will always be 'self-oriented', since a pronoun can only refer to the belief self (with self-awareness on part of the attitude holder), in which case it is de se, or not, in which case it is not de se. By contrast, in dream reports, the de se reading may vary in this respect; it can target an individual distinct from the dreamer, as in (2a), but it can also become 'self-oriented' when the dream self is identical to the dreamer (which one may argue to be the default state); this is illustrated in (3). Since (3a) and (3b) will generally be truth-conditionally equivalent, the slightly more artificial scenario in (3c) has been added, which emulates a typical mistaken identity context within a dream context. For a reader, it is worth being aware of these differences between belief reports and dream reports, which are clearly not trivial.

(3) John dreams of a soccer match that Bill and John are a part of. The dream is from John's own perspective, i.e. he does not dream to be anyone else.

a. de se context: In this dream, John just scored a goal.

John dreams that he $\mathbf{~}_{\text {de }}$ ( $=\mathbf{J o h n} /$ the dream self $)$ just scored a goal.

b. (non-de se) de re context 1: In this dream, John just scored a goal.

John dreams that $\mathbf{h e}_{\text {de re }}(=\mathbf{J o h n} /$ the actual dreamer $)$ just scored a goal.

c. (non-de se) de re context 2: In this dream, John witnesses that someone, who he sees at a distance, just scored a goal. Only later in the dream, John will realize that the person who scored the goal was actually John himself, through a mirror placed in the distance, unable in this particular dream world to recognize his own bodily movements.

John dreams that he $\mathbf{d e}_{\text {re }}(=\mathbf{J o h n} /$ the man John sees at a distance) just scored a goal.

\subsection{Introducing the debate}

There are currently two prominent approaches that aim to explain the distribution of de se and (non-de se) de re pronouns - both of which have often focused on highly specialized forms of de se pronouns, such as logophors (see Schlenker 2003, Pearson 2012).

The first type of analysis claims that de re construals come in a non-de se flavor (as in (1b)), and in a de se flavor (as in (1a)), i.e. the de se reading is a specialized de re reading; see Lewis (1979), Reinhart (1990), Maier (2009) and Santorio (2014). To see how this works, it is worth briefly introducing the current standard account of (non-de se) de re pronouns. The standard approach holds that (all) de re pronouns involve some sort of acquaintance relation between the attitude holder and the referent in the actual world (following Kaplan 1968, Lewis 
1979; see Santorio 2014 and Pearson 2015 for a recent discussion); informally speaking, the pronoun he in (1b) refers to John in the actual world, but to derive the intuitive truth conditions of (1b), he has to be mapped to an individual who satisfies the property of being the man that John as the attitude holder is watching in the video. In other words, the de re reading requires an acquaintance relation to hold between John (as the referent of John) and John (as the referent of $h e$ ), which (simplified for present purposes) amounts to the relation $R(x, y)=x$ is the individual that $y$ is watching in the video (cf. Lewis 1979:541-542). Therefore, what (1b) conveys is the following: (i.) John is related to himself by means of an acquaintance relation $R$ (here: John himself being the individual that John is watching in the video), and (ii.) John believes that the individual who is related to him via that acquaintance relation $R$ (i.e. the man who he is watching in the video) is tall. See Percus \& Sauerland (2003a), Santorio (2014), and Pearson (2015) for formal implementations of such a view. Approaches that derive de se readings from a de re semantics assume that de se readings simply involve a special type of 'self' acquaintance relation, which we could state (simplified, as above) as the relation $R(x, y)=x$ is the individual that $y$ identifies with. (1a) would thus convey the following: (i.) John is related to himself by means of the 'self' acquaintance relation $R$ (here: John being the individual that John identifies with), and (ii.) John believes that the individual who is related to him via the 'self' acquaintance relation $R$ (i.e. the individual who he identifies with) is tall. In brief, the difference between (1a) and (1b) solely amounts to the choice of acquaintance relationship, while both have a de re semantics under such a ("de se as de re + self-acquaintance") view.

The alternative view on how to derive de se and (non-de se) de re readings argues in favour of a dedicated de se LF, and thus draws a more fundamental distinction between the two readings, as in Percus \& Sauerland (2003b); the core difference for our purposes concerns the interpretation of de se construals in such a view. Percus \& Sauerland (2003b) argue that an embedded de se pronoun is an uninterpreted pronoun, which must move to the clausal periphery, triggering lambda abstraction, to turn the embedded clause into a property-denoting expression. In line with Percus \& Sauerland (2003b), whose focus is on de se pronouns with dedicated de se LFs, I simplify the interpretation of de re pronouns, glossing over concept generators (cf. Percus $\&$ Sauerland 2003a, Pearson 2012, Santorio 2014); these are generally assumed to formalize the acquaintance relations discussed above, which is orthogonal to the core question under investigation. Correspondingly, a lexical entry for believe can be given as in (4).

(4) $[[\text { believe }]]^{\mathrm{g}}=\lambda \mathrm{P}_{<\mathrm{e},<\mathrm{s}, \mathrm{\downarrow}>>} . \lambda \mathrm{x} . \lambda \mathrm{w}$. For all $<\mathrm{y}, \mathrm{w}^{\prime}>$ in $\mathrm{DOX}_{\mathrm{x}, \mathrm{w}}, \mathrm{P}(\mathrm{y})\left(\mathrm{w}{ }^{\prime}\right)=1$

where DOX $X_{x, w}$ stands for the set of pairs $\left\langle y, w^{\prime}>\right.$ such that $w^{\prime}$ is a world compatible with $x$ 's beliefs in $w$, and $y$ is the individual in w' who $x$, in $w$, identifies as himself. (based on Percus \& Sauerland's 2003b entry for dream)

Note that I will be focusing on dream, rather than believe, throughout much of this paper. The core assumption in this respect is that different attitude predicates can be modeled in parallel (see also Pearson 2012:9). ${ }^{2}$ In fact, Percus \& Sauerland (2003b) posit the lexical entry in (5) (which (4) is based on) for dream as opposed to believe; here, the complement clause of dream denotes a property, and dream quantifies over so-called centered worlds, i.e. pairs of an individual variable $y$ and a world $w$ ' such that the following holds. If $\langle\mathrm{y}, \mathrm{w}$ ' $>$ are part of the 'dream worlds' of the matrix subject $x$, then, for any dream world $w^{\prime}, y$ is the individual that $x$ identifies with in $w$ ', i.e.

\footnotetext{
2 There is a question of whether believe-type predicates and dream-type predicates should be given the same analysis; see Anand (2006) and Pearson \& Dery (2014) for discussion. I come back to this later.
} 
the dream self. Correspondingly, dream asserts that every pair $<\mathrm{y}, \mathrm{w}{ }^{\prime}>$ has the property denoted by the complement clause.

(5) $[[\mathrm{dream}]]^{\mathrm{g}}=\lambda \mathrm{P}_{<\mathrm{e},<\mathrm{s}, \mathrm{t}>>} . \lambda \mathrm{x} . \lambda \mathrm{w}$. For all $<\mathrm{y}, \mathrm{w}^{\prime}>$ in $\mathrm{DREAM}_{\mathrm{x}, \mathrm{w}}, \mathrm{P}(\mathrm{y})(\mathrm{w} ')=1$
where DREAM $M_{x, w}$ stands for the set of pairs $<y, w^{\prime}>$ such that $w^{\prime}$ is a world compatible
with $x$ 's dream in $w$, and $y$ is the individual in $w^{\prime}$ who $x$, in $w$, identifies as himself.

(Percus \& Sauerland 2003b)

There is a non-trivial question (which I already hinted at in section 2.1) of how the labels 'de se' and 'de re' apply across different types of attitude predicates. If we assume (4) and (5) as the lexical entries of believe and dream, we see that each of them introduces an individual $y$ such that the attitude holder $x$ identifies with $y$ in her 'believe worlds' or her 'dream worlds', respectively. For the purposes of this paper, I will use the term 'de se reference' for reference to any such $y$ individual (which may thus be the attitude holder's 'belief self' or 'dream self', depending on the predicate).

Example (6) is an illustration of how de se readings are derived with a predicate such as dream. (Note that believe would be parallel to dream, modulo substituting DOX for DREAM.) In words, the de se LF in (6) involves the following components. The embedded de se pronoun he is uninterpreted (as marked by the asterisk) and moves to the left periphery of the embedded clause. There, the de se pronoun triggers predicate abstraction over the argument slot that is associated with it; as a consequence, this argument slot thus ends up being identified with the center of the worlds compatible with John's beliefs (in the case of believe), i.e. with John's 'belief self' (or 'dream self' in the case of dream). It is worth emphasizing that the exact rendering of dedicated de se LFs is independent from the more basic idea that dedicated de se LFs are necessary. For concreteness' sake, I adopt the rendering of Percus \& Sauerland, but this is by no means the only possible way of formalizing a dedicated de se LF.

(6) Percus \& Sauerland (2003b) style de se LF (for a dream report)

a. John dreams (that) he $\mathbf{h}_{\text {de se }}$ is tall.

b. de se LF: John dreams (that) he* $\lambda_{1}\left[\mathbf{t}_{1}\right.$ is tall].

VP

[[ John dreams $\left(\right.$ he $\left.^{*}\right) \lambda_{1} \mathrm{t}_{1}$ is tall $\left.]\right]^{\mathrm{g}}$

$=\lambda \mathrm{w}$. For all $<\mathrm{y}, \mathrm{w}^{\prime}>$ in DREAM Dohn,w $_{\mathrm{w}}, \mathrm{y}$ is tall in $\mathrm{w}$,

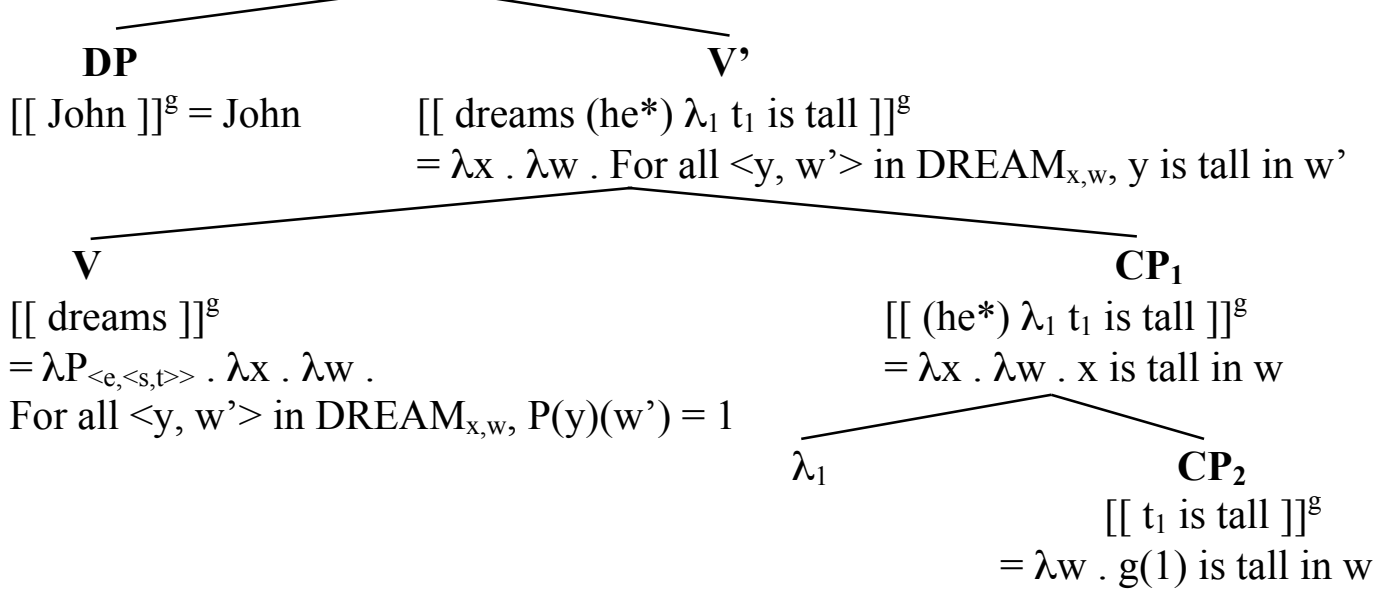


Since Percus \& Sauerland do not derive de se readings as a special type of de re reading, I will simplify and write 'de re' instead of '(non-de se) de re' from now on, except for situations in which this simplification may be confusing. The aspect of the de se vs. de re distinction that is most important for our present purposes is the idea that de re LFs lack pronoun movement, since there is no embedded element that ends up being identified with the 'dream self' or 'belief self'. A simplified de re $L F$ is given in (7). This LF (based on Percus \& Sauerland 2003a,b) contains two crude simplifications. First, de re pronouns are assumed to be directly referential (cf. Percus \& Sauerland 2003a, Pearson 2012, Santorio 2014, Pearson 2015, amongst others, for a discussion of formalising acquaintance relations by means of so-called concept generators). Second, in order to maintain a single lexical entry for dream(/believe) in de se LFs and dream(/believe) in de re LFs, I follow Percus \& Sauerland (2003a) and assume a type-shifting operator PROP, which introduces a vacuous individual argument position. PROP thus vacuously turns the embedded proposition (of type $<\mathrm{s}, \mathrm{t}>$ ) into a property (of type $<\mathrm{e},<\mathrm{s}, \mathrm{t}>>$ ). For dream reports, the difference between (6) and (7) becomes relevant whenever John dreams that he is someone other than John (i.e. when the dream self is not identical to the dreamer), such as Bill. In such a situation, the LF in (6) has John ascribing tallness to his dream self, Bill, and not to John, the dreamer. By contrast, (7) has John ascribing tallness to John in the real world, i.e. to the dreamer, regardless of who he is in his dreams.

(7) Percus \& Sauerland (2003b) style de re LF

a. John dreams (that) he $\mathbf{d e ~}_{\mathbf{r}}$ is tall.

b. de re LF (simplified): John dreams PROP he $\mathbf{2}_{\mathbf{2}}$ is tall. where $\mathrm{g}=[2 \rightarrow \mathrm{John}]$ VP

$[[\text { John dreams PROP he } 2 \text { is tall }]]^{\mathrm{g}}$

$=\lambda \mathrm{w}$. For all $<\mathrm{y}, \mathrm{w}^{\prime}>$ in DREAM $\mathrm{Dohn}_{\mathrm{w}}, \mathrm{g}(2)$ is tall in $\mathrm{w}$ '

$=\lambda \mathrm{w}$. For all $<\mathrm{y}, \mathrm{w}^{\prime}>$ in DREAM John,w, $_{\mathrm{w}}$ John is tall in $\mathrm{w}^{\prime}$

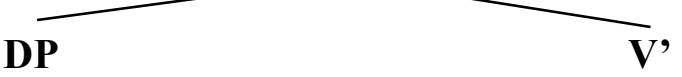

$[[\mathrm{John}]]^{\mathrm{g}}=\mathrm{John} \quad\left[\left[\text { believes PROP he } \mathrm{h}_{2} \text { is tall }\right]\right]^{\mathrm{g}}$

$=\lambda \mathrm{x} . \lambda \mathrm{w}$. For all $<\mathrm{y}, \mathrm{w}{ }^{\prime}>$ in $\operatorname{DREAM}_{\mathrm{x}, \mathrm{w}}, \mathrm{g}(2)$ is tall in $\mathrm{w}^{\prime}$

$$
\begin{gathered}
\mathbf{V} \\
=\lambda[\text { believes }]]^{\mathrm{g}} \\
=\mathrm{P}_{<\mathrm{e},<\mathrm{s}, \mathrm{t}>>} \cdot \lambda \mathrm{x} \cdot \lambda \mathrm{w} .
\end{gathered}
$$

For all $<\mathrm{y}, \mathrm{w}^{\prime}>$ in $\operatorname{DREAM}_{\mathrm{x}, \mathrm{w}}, \mathrm{P}(\mathrm{y})\left(\mathrm{w}^{\prime}\right)=1$

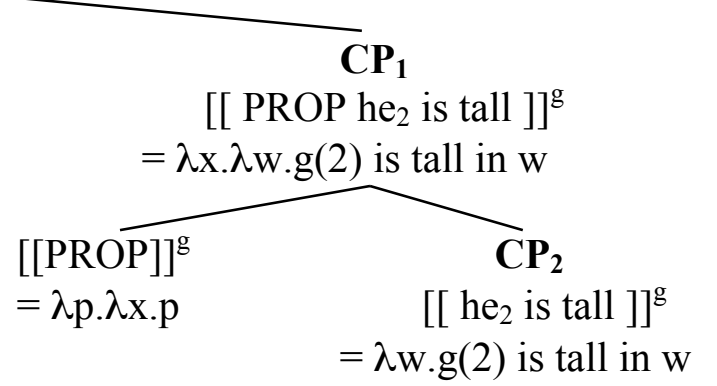

To recapitulate, from the perspective of Percus \& Sauerland (2003a,b), de se LFs contain a semantically uninterpreted pronoun (marked by an asterisk), which moves to the left periphery of the clause and triggers predicate abstraction. By contrast, de re LFs do not contain such semantically uninterpreted pronouns and lack such pronoun movement. Alternatively, Reinhart (1990), Maier (2009) and Santorio (2014) argue that dedicated de se LFs are not required: specifically, de se interpretations are derived as a special type of de re interpretations. The question at this point is how to tease apart the two approaches. I review an argument from the literature in section 2.3. 
Before discussing the argument for dedicated de se LFs, it is worth focusing on one point of agreement between Percus \& Sauerland (2003a,b) and the competing approaches. For de re LFs, which I presented in a highly simplified manner in (7), a Lewisian approach assumes that there is an acquaintance-based relationship between the attitude holder and the individual denoted by the de re pronoun (Lewis 1979:541-542). With respect to example (8a), repeated from (1b), this means that the de re interpretation is equivalent to (8b), i.e., de re beliefs actually incorporate de $s e$ variables; these are presumably contained in a larger covert constituent, the $\operatorname{res} P$, at LF (see also Anand 2006, and compare Pearson 2015:84-89 for a detailed recent discussion of this theoretical background). A crucial component of (8b) is the acquaintance relation $x$ saw $y$ in the video that holds between the attitude holder $x$ and the de re referent $y$. Note that, since we are discussing approaches without a dedicated de se $L F$, the informally rendered he $e_{d e}$ in $(8 \mathrm{~b})$ and (9b) should not be confused with the uninterpreted de se pronouns of Percus \& Sauerland.

(8) a. (non-de se) de re context: John watches a video of himself playing soccer, not recognizing himself and thinks: "That man in the video is tall."

John believes that he $\mathbf{d e}_{\mathrm{de}}$ is tall.

b. de re pronoun modeled as a definite description (the resP) that embeds a de se variable

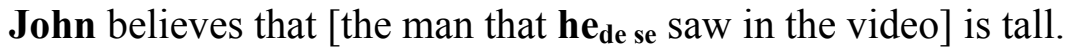

A de se interpretation can always arise from an acquaintance-based de re LF along the lines of (8b) as long as the salient acquaintance relation is self-acquaintance (i.e., $x$ identifies with $y$ ); this is sketched in (9b) for the prototypical de se context in (1a)/(9a).

(9) a. de se context: John looks at himself in the mirror and thinks: "I am tall."

b. derivation of de se via de re + self-acquaintance

John believes that he $\mathbf{e}_{\text {de re }}\left(=\left[\right.\right.$ the man that he $\mathbf{e}_{\text {de se }}$ identifies with $\left.]\right)$ is tall.

Even dedicated de-se-LF approaches such as Percus \& Sauerland (2003a,b), whose approach to de re pronouns builds on Lewis (1979), must allow for de se readings to arise from de re pronouns in combination with self-acquaintance.

They provide empirical argument for maintaining the option of de se via de re in the form of example (10) (adapted from Percus \& Sauerland 2003a). In (10a), John holds a de re belief that happens to be about himself; therefore, (10b) must have a de re LF (and cannot have a dedicated de se LF). Nevertheless, (10b) is judged to be false in context (10a), due to Bill's de se belief. Crucially, Bill's de se belief must derive from a de re LF with self-acquaintance, since a de se LF is not available in (10b) (and its focus alternatives).

(10) a. Context: Drunk election candidates are watching campaign speeches on TV, and do not recognize themselves in the broadcast. John, who is depressive, thinks "I'll lose", but is impressed by the speech that happens to be his own and is sure "that candidate" will win. Bill, who is confident, believes "I'll win". Tony, who is depressive, believes "John will win."

b. Only John thinks he'll win the election.

In other words, the disagreement between the two types of approaches is whether there are dedicated de se LFs in addition to the option of deriving de se from de re with self-acquaintance, or whether such dedicated de se LFs are unmotivated. Percus \& Sauerland's (2003a,b) argument, as presented in section 2.3, is in favor of dedicated de se LFs. 


\subsection{Earlier support for dedicated de se LFs}

As independent empirical motivation for their analysis, Percus \& Sauerland (2003b) introduce the following pattern captured by what they dub the Oneiric Reference Constraint. (I follow the recent discussion of Pearson \& Dery 2014 in this section.) If the complement of dream contains a mix of de re pronouns (that refer to the dreamer) and de se pronouns (that refer to the individual that the dreamer identifies with in the dream), then it is not allowed that all de se pronouns are asymmetrically c-commanded (in their positions before de-se-related movement) by a de re pronoun. Percus \& Sauerland (2003b) argue that this follows from a "feature-based Attract Closest constraint", which they call superiority, quoted in (11a); this constraint rules out configurations of the type in $(11 \mathrm{~b})$. Crucially, since Percus \& Sauerland's superiority is featurebased, it only applies to configurations in which the de se pronoun and the de re pronoun have identical features (e.g. $3^{\text {rd }}$ person, masculine, singular, as in the case of he and his in (12)).

(11)a. "Superiority": At a given point in the derivation, if you are faced with the option of moving two different items $\alpha$ and $\beta$ to the same position, if $\alpha$ asymmetrically ccommands $\beta$, and if $\alpha$ and $\beta$ have the same features, then do not move $\beta$.

b. $\quad * \quad \ldots \lambda_{1}\left[\mathrm{t}_{1} \ldots\left[\operatorname{pro}^{*}\left[\lambda_{2}\left[\ldots \operatorname{pro}_{1} \ldots \mathrm{t}_{2} \ldots\right]\right]\right]\right.$

where pro $_{1}$ asymmetrically c-commands $t_{2}$

(Percus \& Sauerland 2003b)

Essentially, Percus \& Sauerland's (2003b) Oneiric Reference Constraint rules out the generating of dedicated de se LFs by virtue of moving an uninterpreted de se pronoun across an interpreted de re pronoun. To illustrate, consider the example in (12), involving a dream report in which the dreamer (Pooh) dreams to be someone else (namely Piglet). As discussed in section 2.2, the de se reading of a pronoun in such dream reports is (somewhat counterintuitively) the reading where the pronoun refers to the 'dream-self' (i.e., to Piglet or whoever else the dreamer dreams to be). Therefore, if Pooh dreams that he is Piglet, then a de se reading for he/his in (12b) is a reading where he/his refers to Piglet, (12c). By contrast, if a pronoun in such a dream report refers to the actual dreamer (rather than to the individual in the dream), then we are dealing with a de re reading, as in (12d). This is derived from the semantics of dream as repeated in (13). In (13), the center $y$ of the attitude holder's dream worlds $w$ ' is the individual that the dreamer identifies with in her/his dreams (rather than the dreamer herself/himself).

(12) a. Last night Pooh dreamed that he was Piglet.

b. Pooh dreamed that he was stealing his honey.

c. de se referent $=$ 'the dream-self' $=$ Piglet

d. de re referent $=$ 'the dreamer' $=$ Pooh

(adapted from Pearson \& Dery 2014)

(13)

$[[\text { dream }]]^{\mathrm{g}}=\lambda \mathrm{P}_{<\mathrm{e},<\mathrm{s}, \mathrm{t}>>} . \lambda \mathrm{x} . \lambda \mathrm{w}$. For all $<\mathrm{y}, \mathrm{w}{ }^{\prime}>$ in $\operatorname{DREAM}_{\mathrm{x}, \mathrm{w}}, \mathrm{P}(\mathrm{y})\left(\mathrm{w}^{\prime}\right)=1$

where DREAM $M_{x, w}$ stands for the set of pairs $<y, w^{\prime}>$ such that w' is a world compatible with $x$ 's dream in $w$, and $y$ is the individual in $w$ ' who $x$, in $w$, identifies as himself.

(Percus \& Sauerland 2003b) 
As shown by Percus \& Sauerland (2003b), an intriguing set of facts arises for dream reports of this type, in that only three out of four logically possible readings are attested. The four logically possible readings for a sentence like (12b) are given in (14a-d); (14a) would be the reading where both pronouns are read de se, $(14 \mathrm{~b})$ would be the reading where the first pronoun is read de re and the second pronoun de se, and so forth. Percus \& Sauerland (2003b) argue that (due to (11a)(11b)) the de re + de se reading in (14b) is unavailable, while the readings in (14a), (14c) and (14d) are available. Dery \& Pearson (2014) test this experimentally and confirm the empirical claim from Percus \& Sauerland (their Oneiric Reference Constraint), i.e. that (14b) is unacceptable. Moreover, Dery \& Pearson find a contrast between dream reports (Pooh dreamed that ...) and belief reports (Pooh thought that ...) in that belief reports do, in fact, permit the reading (14b). This difference was first observed (without experimental verification) by Anand (2006), and will become relevant again in my discussion in section 3.2.2.

(14) a. Pooh dreamed that Piglet(=de se) was stealing Piglet's(=de se) honey. de se + de se b.\# Pooh dreamed that $\operatorname{Pooh}(=d e$ re $)$ was stealing Piglet's(=de se) honey. de re + de se c. Pooh dreamed that Piglet(=de se) was stealing Pooh's(=de re) honey. de se + de re d. $\mathbf{P o o h}$ dreamed that $\mathbf{P o o h}(=d e$ re $)$ was stealing $\mathbf{P o o h}$ 's(=de re) honey. de re + de re (adapted from Pearson \& Dery 2014)

In the Percus \& Sauerland system, the pattern in (14a-d) (which is puzzling for competing analyses) follows from independently motivated syntactic constraints on movement. Specifically, the superiority constraint in (11a) can be seen as an instantiation of more general locality constraints (in the spirit of Chomsky's 1995 Minimal Link Condition). To conclude, we can illustrate superiority for (14b) and (14c), as in in (15) and (16), respectively. Superiority is met in (15), but violated in (16), thus excluding the de re + de se reading.

(15) de-se + de-re reading

a. $\quad{ }^{K}$ Pooh dreamed that he de-se $_{\text {( }}$ = Piglet) was stealing [his de-re $_{\text {( }}$ (= Pooh's) honey].

b. LF: Pooh dreamed [CP $\mathbf{h e} * \lambda \mathbf{x}_{\mathbf{1}}\left[\mathbf{t}_{\mathbf{1}}\right.$ was stealing his $\mathbf{s e}_{\text {dere }}$ honey]].

(16) de-re + de-se reading

a. * Pooh dreamed that he $\mathbf{h e}_{\text {de-re }}$ (= Pooh) was stealing [his de-se $_{\text {( }}$ (= Piglet's) honey].

b. LF: Pooh dreamed [CP his* $\lambda \mathbf{x}_{\mathbf{1}}\left[\mathbf{h e}_{\text {de-re }}\right.$ was stealing $\mathbf{t}_{\mathbf{1}}$ honey]].

Note that Percus \& Sauerland (2003b) use the name "superiority" as a mnemonic, but it is unclear whether they intend to subsume their constraint (11a) under the traditional superiority condition of Chomsky (1973). As pointed out by an anonymous reviewer, this distinction is relevant, since I discuss data from German dialects in section 3, and it is controversial whether the traditional superiority condition is active in German (see Grewendorf 1988, Wiltschko 1997 for different views on this issue). However, the controversy in German mainly targets superiority in multiple wh-questions; it is thus unclear to what extent the relevant arguments and concerns 
would carry over to the Oneiric Reference Constraint of Percus \& Sauerland (2003b) (but see section 3.2 .3 for a discussion).

If we now compare Percus \& Sauerland (2003a,b) to a Lewisian approach, such as Reinhart (1990), Maier (2009) and Santorio (2014), it is worth focusing on the explanatory power of the two types of approach. In both types of approach, de se variables must somehow be bound by a suitable operator. Recall the above discussion on deriving de se readings from de re pronouns with self-acquaintance; the Lewisian view is that de se readings only derive in such a way, as in (17), repeated from (9); i.e., there are no dedicated de se LFs. ${ }^{3}$

(17) a. de se context: John looks at himself in the mirror and thinks: "I am tall."

b. derivation of de se via de re + self-acquaintance

John believes that he $\mathbf{d e}_{\mathbf{d e}} \mathbf{( =}$ [the man that he $\mathbf{d e}_{\mathbf{d e}}$ identifies with $\left.]\right)$ is tall.

The important question here is how restrictive/explanatory the two types of approaches are (i.e., with vs. without dedicated de se LFs). In a Lewisian approach (without dedicated de se LFs), de $r e$ readings and de se readings can both be modeled as arising from a de se variable contained within a larger covert constituent (resP), which also contains the relevant acquaintance relation, and which is pronounced as the de re pronoun, cf. (17b). In fact, for the (independently needed) binder operator that connects the de se variable to the attitude predicate, a Lewisian approach without dedicated de se LFs requires that it only binds de se variables within de re expressions (resPs). By contrast, Percus \& Sauerland (2003a,b) assume that de se variables can be located freely in a clause, with the highest de se pronoun being linked to the binder operator via movement. If we compare the two approaches in terms of restrictiveness, Percus \& Sauerland $(2003 \mathrm{a}, \mathrm{b})$ thus only posit one restriction on de-se related binding, the Oneiric Reference Constraint, which is derived from the assumption of an independently needed syntactic constraint "Attract Closest". By contrast, a Lewisian approach has to posit an additional restriction on binding, i.e., that de se variables can only ever be contained within de re pronouns, as in (17b).

To conclude this section, recall that Percus \& Sauerland's (2003a,b) system was originally conceived for English, which is relatively minimal in its pronominal system: while English has one core paradigm of personal pronouns $(I, y o u$, he/she/it, ...), other languages make systematic distinctions, e.g. between clitic and full personal pronouns, or between null and overt pronouns. I now proceed to focus on such pronominal classes in light of the present discussion.

\section{3. de se vs. de re interpretations: the view from pronominal classes}

In this section, I revisit the de se vs. de re distinction in languages which have richer pronominal paradigms than English. In section 3.1, I present my take on anaphora, where I argue that different languages that contain a richer pronominal inventory make parallel distinctions between 'stronger' pronouns and 'weaker' pronouns. In section 3.2, focusing on Kutchi Gujarati and Bavarian, I show how such distinctions interact with the de se vs. de re distinction in dream reports. Subsequently, section 3.3 shows that similar effects can also be observed for belief reports.

Prior to delving into this discussion, it is worth emphasizing the core aims of this paper; on the empirical side, this paper shows that the morphosyntactic complexity of pronouns correlates

\footnotetext{
${ }^{3}$ Consider in this connection the following quote from Lewis (1979:543): "Self-ascription of properties is ascription of properties to oneself under the relation of identity. Certainly identity is a relation of acquaintance per excellence. So belief de se falls under belief de re".
} 
with available readings (i.e., de se vs. de re readings). However, and more importantly, on the theoretical side, I develop a novel hypothesis concerning the interconnectedness of morphosyntax and meaning, namely that the semantic interpretation of pronouns is strongly interlinked with their internal structure, i.e., with the amount of functional material that they project. A critical reader may wish to take note of this goal, which transcends (while incorporating) a mere aim of deriving available readings from pre-established principles.

\subsection{Pronominal classes and de se vs. de re readings}

\subsubsection{Predictions and expectations: preliminaries}

Before exploring languages with richer pronominal systems, it is worth addressing the core expectation that arises from previous research on de se and de re readings. In particular, the Percus \& Sauerland (2003a,b) analysis assumes that de se pronouns must be uninterpreted in order to give rise to a dedicated de se $\mathrm{LF}^{4}$ as shown in (6) (in section 2.2), where such uninterpreted pronouns are marked by an asterisk. Turning to distinctions amongst pronominal paradigms in a given language, Cardinaletti \& Starke (1999:156) observe that (within their tripartite classification of pronouns as clitic, weak and strong) semantically vacuous dummy pronouns cannot be strong pronouns. This is illustrated for the French strong pronoun lui 'he' (with weak counterpart $i l$ 'he') in (18). If we assume that it is a general fact about semantically vacuous pronouns that they must be weak, we derive the prediction that only weak pronouns can be construed de se (and possibly only the weakest pronouns, as we will see).

(18) a. Il pleut.

he rains

'It is raining.'

b.* Lui (il) pleut.

he he rains

(Cardinaletti \& Starke 1999:154)

Cardinaletti \& Starke argue that the ungrammaticality of (18b) can be derived from structural economy constraints, such as (19); I adopt such a view, though I propose (in section 3.1.2) that (19) can be subsumed by a generalized constraint Minimize DP!, as proposed in Patel-Grosz \& Grosz (2017:279).

(19) Choice of a pronoun

Choose the most deficient possible form.

(Cardinaletti \& Starke 1999:153)

\subsubsection{Analyzing pronominal classes: a descriptive strength hierarchy}

Many languages (other than English) have several pronominal classes, e.g. null vs. overt pronouns or clitic vs. non-clitic pronouns (cf. Cardinaletti \& Starke 1999, Dechaine \& Wiltschko 2002). It can be shown that these classes share a strength hierarchy, illustrated in (20). Null and clitic pronouns classify as the weakest type of pronoun, compared to strong personal pronouns, and the even stronger demonstrative pronouns. (Note that this strength hierarchy does not reflect

\footnotetext{
${ }^{4}$ Percus \& Sauerland (2003a:240) describe this type of dedicated de se pronoun as "an element that has no interpretation on its own, but can move, leaving behind a lambda and a trace".
} 
the analysis of Cardinaletti \& Starke 1999, who assume that personal pronouns and demonstrative pronouns belong to different categories.)

pronominal strength hierarchy (simplified)

null pronoun / clitic personal pronoun $<$ strong personal pronoun $<$ demonstrative pronoun

Evidence for (20) is provided in Patel-Grosz \& Grosz (2010), who argue that different languages 'slice the hierarchy' in different ways, giving rise to similar effects (which can, in turn, be used as diagnostics). For example, Bosch et al. (2003) and Bosch \& Umbach (2007) observe that German demonstrative pronouns (like $d e r$ 'he, that one') cannot refer to the current aboutness topic, as shown in (21a) (see also Reinhart 1995, Hinterwimmer 2015). What we observe is that many languages (e.g. Portuguese, French, Hebrew) exhibit the same effect, as shown in (21b), where the Portuguese demonstrative pronoun esta patterns like the German demonstrative pronoun $d e r$, and the Portuguese personal pronoun ela patterns like the German personal pronoun er.

\section{(21)a. (Standard) German}

Hans 1 wollte mit Paul $\mathbf{2}_{\mathbf{2}}$ joggen, aber $\left\{\mathbf{e r}_{\mathbf{1 / 2}} / \mathbf{d e r}_{\mathbf{2} / * \mathbf{1}}\right\}$ war krank. Hans wanted with Paul jog but he DEM was sick 'Hans wanted to go running with Paul, but he was sick.' (cf. Bosch et al. 2003)

b. (Brazilian) Portuguese

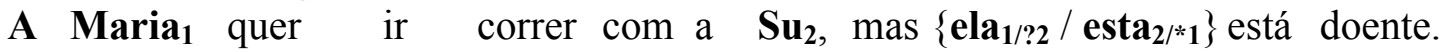
the Maria wanted to.go to.run with the Sue but she DEM was sick 'Maria wanted to go running with Sue, but she was sick.'

Assuming the strength hierarchy in (20), we can capture the pattern in (21a-b) by the schema in Figure 1a. (The illustrated pronoun classes are contained in boxes.)

Figure 1a: personal-vs-demonstrative languages

null pronoun / clitic personal pronoun $<\underset{\substack{\text { strong personal pronoun } \\ \checkmark \text { TOPIC-REFERENCE }}}{\mathbf{x} \text { TOPIC-REFERENCE }}$

Surprisingly, other languages slice the hierarchy differently, while generating the same effect; here, the relevant contrast is between null and overt (personal and demonstrative) pronouns, as shown in (22a) and (22b). The data from Kutchi Gujarati and Czech show that only the null pronoun can refer to the current aboutness topic. Furthermore, the Czech data in (22b) show that even where there is a choice between a demonstrative pronoun and an overt personal pronoun, only the weakest possible pronoun can refer to the aboutness topic, namely the null one.

(22)a. Kutchi Gujarati

$\mathbf{J o h n}_{1}$-ne Paul $_{2}$ saathe dhorva javu thu, pun $\left\{\boldsymbol{p r o s}_{\mathbf{1 / \# \mathbf { 2 }}} / \mathbf{i}_{\mathbf{2} / * \mathbf{1}}\right\}$ thandithi aavi thi. John-DAT Paul with run.INF go AUX but pro he cold came AUX 'John wanted to go running with Paul. But he had a cold.'

b. Czech

Věra ${ }_{1}$ chtěla jít běhat $\mathrm{s} \quad$ Marií $_{2}$, ale $\left\{\boldsymbol{p r o s}_{1 / 2 \mathbf{2}} / \mathbf{o n a}_{2 / * 1} / \mathbf{t a}_{2 / *}\right\}$ byla nemocná. Vera wanted go:inf run:inf with Marie but pro she DEM was sick 'Vera wanted to go jogging with Marie, but she was sick.' 
The observations in (22a-b) thus give rise to the generalization in Figure $1 \mathrm{~b}$. While there are personal-vs-demonstrative languages (Figure 1a), there are also null-vs-overt languages.

Figure 1b: null-vs-overt languages

\begin{tabular}{l:c} 
null pronoun / clitic personal pronoun & strong personal pronoun $<$ demonstrative pronoun \\
\hdashline TOPIC-REFERENCE & $\boldsymbol{x}$ TOPIC-REFERENCE
\end{tabular}

In brief, we have seen that Kutchi Gujarati and Czech make a similar distinction as German and Portuguese, dividing pronouns into 'weaker' pronouns that can refer to the current aboutness topic, and 'stronger' pronouns that cannot. However, the two types of languages seem to slice the 'strength hierarchy' at different points. Focusing on Standard German, (21a) and Kutchi Gujarati, (22a), I now proceed to show that the anti-topicality constraint in Figure 1a and Figure 1b correlates with other constraints that correspond to the same distinctions on the strength hierarchy.

First, Patel-Grosz \& Grosz (2010) observe a parallel concerning the ability of pronouns to occur without an explicit antecedent. I provide German and Kutchi Gujarati examples in (23) and (24), but analogous effects arise in other languages. The data in (23) and (24) show that in the absence of an overt antecdent, the weaker pronouns, the personal pronoun er 'he' in German and the null pronoun in Kutchi Gujarati are required. The stronger pronouns, namely the demonstrative der 'he, that one' in German and the personal pronoun $i$ 'he' in Kutchi Gujarati are unacceptable in such environments. As shown in Figure $2 a$ and Figure $2 b$, the observed distinction between strong vs. weak pronouns is parallel to the one that we saw in Figure 1a and Figure $1 \mathrm{~b}$ (i.e. the cut in the hierarchy is at the same point in a given language).

Figure 2a: personal-vs-demonstrative languages

null pronoun / clitic personal pronoun $<\underset{\text { strong personal pronoun }}{\checkmark} \underset{\text { ANTECEDENTLESS }}{\mathbf{x} \text { ANTECEDENTLESS }}$

(23) (Standard) German

Wenn ich schwanger werde, werde ich $\{$ es $/ *$ das $\}$ auf jeden Fall behalten.

if I pregnant become will I it DEM on every case keep

'If I get pregnant, I will definitely keep it (= the baby).' (based on Roelofsen 2008:92)

Figure 2b: null-vs-overt languages

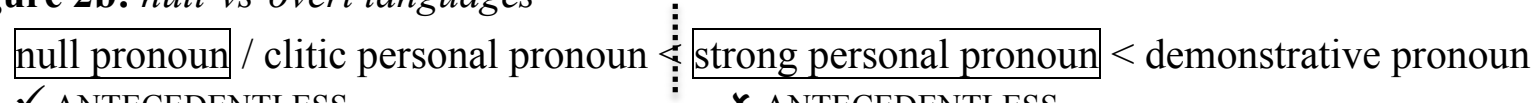

$\checkmark$ ANTECEDENTLESS

$\times$ ANTECEDENTLESS

(24) Kutchi Gujarati

ji penelo manas gare aave, tho i $\{$ pro /*ene $\}$ bak bharave.

if married man home comes then he pro her hug makes

'If a married man comes home, he hugs her (= his wife).'

We can also observe a parallel concerning the ability of pronouns to be bound by a subject quantifier. Once again, paralleling the observations in Figures 1a, 1b, $2 a$ and $2 b$, we find the following. In quantifier-variable-binding configurations, only the weaker pronouns are possible, 
i.e. the personal pronoun in Standard German, and the null pronoun in Kutchi Gujarati, as shown by the examples in (25) and (26).

Figure 3a: personal-vs-demonstrative languages

null pronoun / clitic personal pronoun $<$ strong personal pronoun demonstrative pronoun $\checkmark$ BINDING $\quad \times$ BINDING

(25) (Standard) German

Jeder $\operatorname{Mann}_{1}$ behauptet, dass $\left\{\mathbf{e r}_{1} / * \mathbf{d e r}_{1}\right\}$ intelligent ist. every man claims that he DEM intelligent is 'Every man claims that he is intelligent.' (cf. Wiltschko 1998:144)

Figure 3b: null-vs-overt languages

null pronoun / clitic personal pronoun strong personal pronoun $<$ demonstrative pronoun

$\checkmark$ BINDING $\quad x$ BINDING

(26) Kutchi Gujarati

Batha manas ${ }_{1}$ kidhu ke $\left\{\right.$ pro $\left._{1} / * \mathbf{i}_{1}\right\}$ hosiyar che.

every man said that pro he intelligent is

'Every man said that he was intelligent.'

The above data form a descriptive generalization, which is that pronouns that are higher on the strength hierarchy, and thus qualify as 'stronger', pattern together in ways that set them apart from 'weaker' ones. One of the most prominent analyses that captures this generalization is that strong pronouns have more structure than weaker pronouns; cf. Wiltschko (1998), Cardinaletti \& Starke (1999) Dechaine \& Wiltschko (2002), and Patel-Grosz \& Grosz (2010, 2017).

\subsubsection{An analysis of pronominal classes at the syntax-semantics interface}

One possible rendering of this analysis, as proposed in Dechaine \& Wiltschko (2002), based on Wiltschko (1998), is given in (27) for the contrast between demonstrative pronouns and personal pronouns. In this view, demonstrative pronouns have the structure of full DPs (Wiltschko 1998:149), as shown by (27b), whereas (weak) personal pronouns spell out $\phi P s$ (Dechaine \& Wiltschko 2002:439), (27a). It is orthogonal to the present discussion whether personal pronouns contain a null NP; Wiltschko (1998:149) argues that they do not, but Dechaine \& Wiltschko (2002:439) suggest that personal pronouns may allow for both options: ones that contain an NP and ones that do not. Either way, Wiltschko (1998:165) argues that her analysis derives the binding asymmetry in (25), since demonstrative pronouns are full DPs and thus subject to Condition C. Furthermore, Wiltschko (1998:163-164) argues that this analysis captures the fact that strong (here: demonstrative) pronouns require a suitable antecedent more rigidly than weak pronouns, since strong pronouns necessarily involve NP deletion, which must be structurally licensed, whereas weak pronouns may lack a null NP and thus be contextually licensed (see also Patel-Grosz \& Grosz 2010, and the critical discussion in Patel-Grosz \& Grosz 2017). 


$$
\stackrel{\phi P}{\phi^{0}}
$$<smiles>O=[PH]C(=O)N1CC1</smiles>

There is a question as to whether Wiltschko's (1998) analysis in (27a) vs. (27b) would carry over to weak vs. strong pronouns in null-vs-overt languages such as Kutchi Gujarati, where null pronouns seem to be weak and overt pronouns seem to be strong. We have seen at least one example from Czech, in (22b), where regular personal pronouns (ona 'she') and demonstrative pronouns ( $t a$ 'that one') are grouped together on the 'strong' side, whereas null pronouns classify as 'weak'. For a perspective that aims to cover such patterns, we can turn to the more nuanced view in Patel-Grosz \& Grosz (2017:271); their idea is that all pronouns contain null NPs and a definite determiner (building on Schwarz 2009), but pronouns vary in terms of the amount of extended functional structure that they contain. As illustrated by (28), Austrian Bavarian ${ }^{5}$ differentiates between clitic personal, strong personal and demonstrative pronominal paradigms (ignoring partial pro-drop, which is a limited phenomenon); see Weiß (1998) for similar data in Bavarian. An illustration of Patel-Grosz \& Grosz's (2017:271) model for the strength hierarchy of Austrian Bavarian is given in (29) (which, in turn, is reminiscent of Cardinaletti \& Starke 1999:195).

\section{a. clitic personal das'a kummt. that $=$ he $_{\mathrm{CL}}$ comes 'that he comes'}
b. strong personal das ea kummt. that he comes 'that he comes'

\section{c. demonstrative das dea kummt. that DEM comes 'that he comes'}

In (29), $D_{\text {det }}$ corresponds to the definite determiner (using the label from Ihsane \& Puskás 2001 and Laenzlinger 2005); $\phi$ encodes the purely formal, grammatical $\phi$-features of a pronoun (e.g. masculine in the case of a German pronoun referring to a Löffel 'spoon', or feminine when it refers to a Gabel 'fork'); $\Sigma$ encodes prosodic features that are needed for a pronoun to form an independent prosodic word (Cardinaletti \& Starke 1999:194-195,197); and, finally, $D_{\text {deix }}$ is a higher $D$ head (again, following Ihsane \& Puskás 2001 and Laenzlinger 2005), which is responsible for an increased anaphoricity that is perceived to hold with demonstrative pronouns and may be responsible for the contrast in (23). ${ }^{6}$

\footnotetext{
${ }^{5}$ The data in this paper were translated by a speaker of an Austrian German variety of Bavarian, and verified with several other speakers. Judgments were shared by speakers from different regions of Austria, including Burgenland, Salzburg, and Vienna.

${ }^{6}$ Note that this implies, based on the observation in (24), that the Kutchi Gujarati overt pronoun also has the 'demonstrative pronoun' structure in $(29 \mathrm{c})$. This is independently plausible, but I leave it an open issue for now.
} 
a. null/clitic pronoun

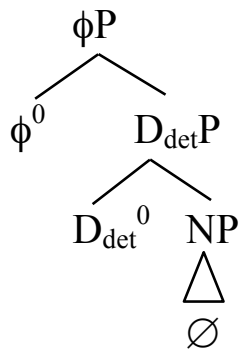

b. personal pron.

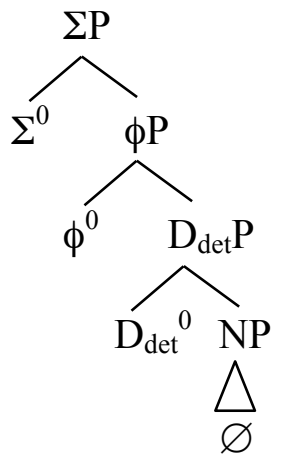

c. demonstrative pron.

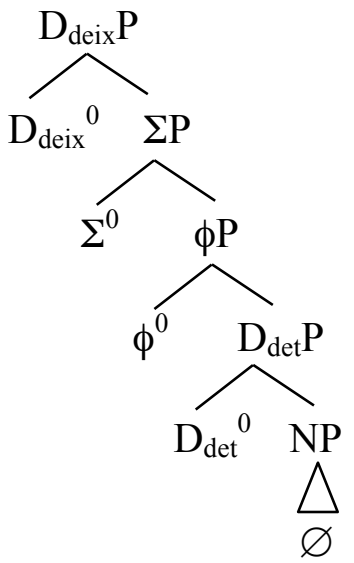

In the spirit of Cardinaletti \& Starke (1999) and Wiltschko (1998), the idea that stronger pronouns contain more structure than weaker pronouns (i.e. that strength correlates with structure) is transparently motivated by their morphosyntax: overall, stronger variants tend to transparently realize more morphemes than their weaker counterparts (e.g. Cardinaletti \& Starke 1999:178); in (28), the masculine demonstrative pronoun (dea) thus seems to morphosyntactically subsume the full personal pronoun $(e a)$, which in turn subsumes the clitic pronoun $(a)$, i.e. we can posit a structural decomposition into [d-[e-[a]]]. The same observation carries over to the neuter pronoun, where the demonstrative pronoun (des 'that one' in Bavarian) subsumes the full personal pronoun ( $e s$ 'it'), which in turn subsumes the clitic pronoun ( $s$ 'it'). (See Wiltschko 1998 for a discussion of feminine and plural pronouns, which superficially appear to deviate from this generalization.)

A more intricate argument for a correlation between 'stronger' and 'more structure' stems from the interaction of pronominal classes and the pragmatic constraint Minimize DP! that I introduce later in this section (in (36)). This constraint penalizes elements with more structure as being uneconomical. The assumption that less structure is more economical is independently motivated (see also Katzier 2011); cross-linguistically, 'strong' pronouns seem to be more marked than 'weak' pronouns, which immediately follows if they have more structure.

Further motivation for structural asymmetry also stems from the idea that the unacceptability of using a stronger pronoun to refer to an implicit antecedent in (23) and (24) can be derived if German demonstrative pronouns (and plausibly also the overt pronouns in Kutchi Gujarati) contain a higher $D_{\text {deix }}$ head, which turns them into more rigidly anaphoric expressions.

Note that (29) takes null pronouns to have less syntactic structure than (non-clitic) overt pronouns. This is a simplification for present purposes, as, for instance, Dechaine \& Wiltschko (2002:439) suggest that, in Japanese, there may be null pronouns that classify as DPs, $\phi P$, and NPs. In other words, they propose that the three overt pronominal classes that they assume may have null counterparts. However, Kutchi Gujarati seems to pattern more like Italian in this respect, for which Cardinaletti \& Starke (1999:175) state: "To the extent that pro is pronominal, it is a deficient pronoun." (See also Cardinaletti \& Starke 1999:198-200) This is motivated in languages like Italian by contrasts like (30a-b), where lui is the non-deficient 'strong' pronoun; semantically vacuous pronouns (e.g. weather it) must be deficient, (30a), whereas ostensive pointing at something requires a strong pronoun, $(30 \mathrm{~b}) .^{7}$

\footnotetext{
${ }^{7}$ For Kutchi Gujarati, such a contrast is difficult to construe, since it does not have 'weather constructions' and ostensive pointing at a thing is accompanied by the demonstrative $a a$ 'that' rather than the pronoun $i$ 'it'.
} 
(30) a. $\left\{{ }^{\mathrm{OK}}\right.$ pro / *lui $\}$ piove molto qui. pro he rains a.lot here

'It rains a lot here.'

b. [pointing at something:] $\quad \begin{array}{r}\left\{{ }^{\mathrm{O}} \mathrm{lui} /{ }^{*} \text { pro }\right\} \\ \text { he è veramente bello }\end{array}$

'It is very nice.'

(Cardinaletti \& Starke 1999:175)

While $\phi^{0}$ and $\Sigma^{0}$ may be taken to be semantically vacuous heads that contain formal features, the distinction between the lower $D_{d e t}$ and the higher $D_{\text {deix }}$ is captured as follows. The lower determiner corresponds to Schwarz's (2009) weak determiner when $D_{\text {deix }}$ is absent, as in (31a), but to his strong determiner when $D_{\text {deix }}$ is present, as in (31b). Omitting $\phi^{0}$ and $\Sigma^{0}$ for simplification, this means that (29a-b) have the LF in (32a), whereas (29c) has the LF in (32b) (from Patel-Grosz \& Grosz 2017:262).

(31) a. $\llbracket$ the $e_{\text {weak }} \rrbracket^{\mathrm{g}}=\lambda \mathrm{s}_{\mathrm{r}} \cdot \lambda \mathrm{P}_{<\mathrm{e}, \mathrm{s} \triangleright}: \exists ! \mathrm{x}\left[\mathrm{P}(\mathrm{x})\left(\mathrm{s}_{\mathrm{r}}\right)\right] . \mathrm{xx}\left[\mathrm{P}(\mathrm{x})\left(\mathrm{s}_{\mathrm{r}}\right)\right]$

b. $\llbracket$ the $e_{\text {strong }} \rrbracket^{\mathrm{g}}=\lambda \mathrm{s}_{\mathrm{r}} \cdot \lambda \mathrm{P}_{<\mathrm{e}, \mathrm{st}} \cdot \lambda \mathrm{y}: \exists \operatorname{\mathrm {x}}\left[\mathrm{P}(\mathrm{x})\left(\mathrm{s}_{\mathrm{r}}\right) \& \mathrm{x}=\mathrm{y}\right] . \mathrm{lx}\left[\mathrm{P}(\mathrm{x})\left(\mathrm{s}_{\mathrm{r}}\right) \& \mathrm{x}=\mathrm{y}\right]$ (Schwarz 2009:148,260,299; stylistically adapted)

a. personal pronoun / PER (er)

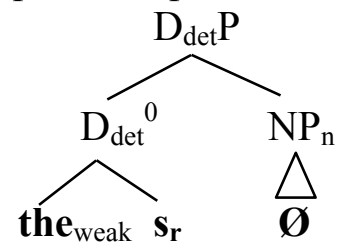

b. demonstrative pronoun / DEM (der)

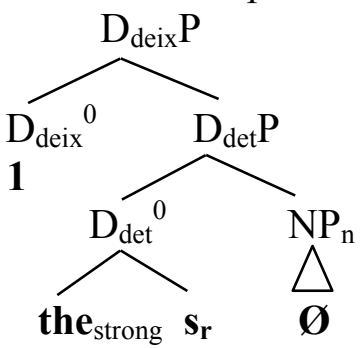

Since (32a) has a clearly defined semantic interpretation, an attentive reader will wonder how semantically vacuous pronouns (not discussed by Patel-Grosz \& Grosz 2017) fit into such a view. Crucially, it is plausible that weak pronouns (such as (28a), but also (28b)) come in two flavours: one variant contains semantically interpreted material, (33a), and thus has the interpretation in (32a) at LF; by contrast, the other variant lacks semantically interpreted material, as in (33b), and merely consists of a purely formal morpho-syntactic $\phi \mathrm{P}$ that is ignored / left uninterpreted at LF. (Note that (33b) is intended as a semantically vacuous element with an uninterpretable $\phi \mathrm{P}$; it should thus not be confused with Dechaine \& Wiltschko's (2002:439) (27a), which may be interpreted as a regular pronoun.)

a. interpreted null/clitic pronoun<smiles>O=[PH]C=[Pb]</smiles>

b. vacuous null/clitic pronoun<smiles>O=[Po]</smiles> 
If semantic vacuity is due to 'internal' deficiency of a pronoun, as in (33b), then uninterpreted pronouns are predicted to arise whenever the extended functional projection (from $\phi \mathrm{P}$ upwards in (28)) is semantically vacuous. This means that demonstrative pronouns, (28c), should never be semantically uninterpreted, as their external $D_{\text {deix }}$ head has a semantic interpretation, as in (32b). This is visualized in (34a) vs. (34b). The element in (34b) is impossible as a semantically vacuous element, because $D_{\text {deix }}$ itself is not vacuous (presumably containing an individual index).

a. interpreted demonstrative pron.

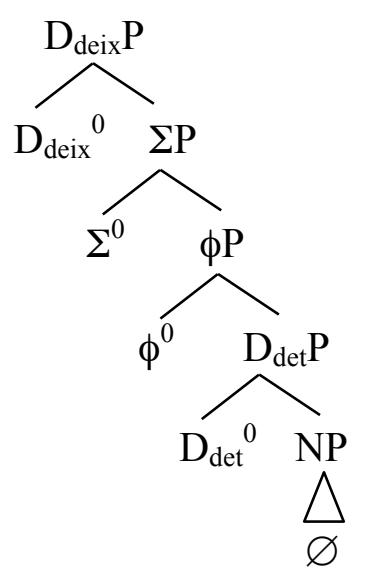

b. *vacuous demonstrative pron.

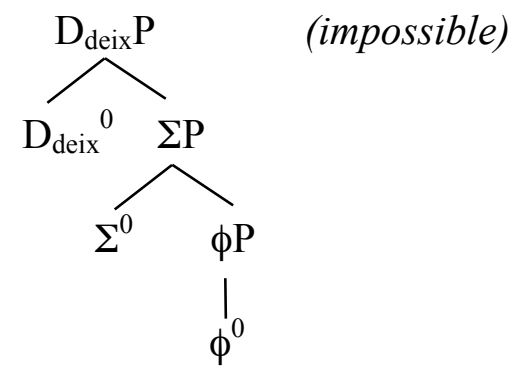

Of course, this means that the intermediate pronouns in the hierarchy, as given in (28b), can be semantically vacuous as long as $\Sigma$ is a purely formal head that is uninterpretable; this is illustrated in (35b). So, there is a question of whether we would still expect asymmetries between the weakest pronouns, in (28a), and the intermediate pronouns, in (28b).

a. interpreted personal pronoun

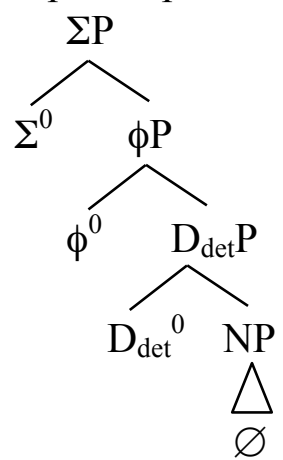

b. vacuous personal pronoun<smiles>[O-][Pb][Te]</smiles>

From the perspective of Patel-Grosz \& Grosz (2017), the general observation that (all) stronger pronouns are more constrained than weaker pronouns (as in section 3.1.3) can be derived via pragmatic economy constraints and independent communicative principles, which require speakers to use the most minimal form of a pronoun unless the less minimal form is independently licensed, as given in (36) (from Patel-Grosz \& Grosz 2017:279). ${ }^{8}$ As a consequence, we expect to find some licensing factor or other to be at play whenever a stronger version does occur, even in contrasting the clitic (28a) to the non-clitic (28b).

\footnotetext{
${ }^{8}$ Minimize DP! is based on Schlenker's (2005b:391) Minimize Restrictors!, Chomsky's (1981:65) Avoid Pronoun, and Cardinaletti \& Starke's (1999:198) Mimise Structure.
} 
An extended NP projection $\alpha$ is deviant if $\alpha$ contains redundant structure, i.e. if

(i) there is an extended NP projection $\beta$ that contains less syntactic nodes than $\alpha$,

(ii) $\beta$ is grammatical and has the same denotation as $\alpha$ (= Referential Irrelevance), and

(iii) using $\alpha$ instead of $\beta$ does not serve another purpose (= Pragmatic Irrelevance)

The goal of this paper is not to evaluate the above-mentioned proposal, but rather to adopt the foundational aspects, and to argue that pronouns with less structure are more likely to be construed de se. One thing that is evident from (21)-(26), if we assume the analysis in (29) is the following. All of the distinctions among weaker and stronger pronouns can be derived from the fact that stronger pronouns have more syntactic structure than weaker pronouns: stronger pronouns (German demonstrative pronouns and Kutchi Gujarati overt pronouns) appear to be 'penalized' for containing surplus structure, in line with structural minimization constraints (Chomsky 1981:65, Cardinaletti \& Starke 1999:198, Schlenker 2005b:391, Patel-Grosz \& Grosz 2017:279). Reconsidering the Percus \& Sauerland (2003a,b) approach to dedicated de se LFs, this raises very clear expectations. In the Percus \& Sauerland view, the following asymmetry arises: pronouns with a de se construal (e.g. $h e^{*}$ ) are actually uninterpreted (i.e. semantically vacuous); their movement alone gives rise to predicate abstraction (similar to relative pronouns in the analysis of Heim \& Kratzer 1998:186). In contrast, pronouns with a de re construal (e.g. he), have a 'normal' interpretation, e.g. as individual variables in the traditional view. Since additional structure (as in (29)) must be licensed by some pragmatic effect or other (in line with Minimize DP!), this entails that the weakest pronoun of a language is the pronoun that is most suitable for remaining uninterpreted, i.e. the weakest pronoun should be the most suitable de se pronoun. The idea is that a stronger pronoun would contain too much structure to remain uninterpreted, which corresponds to Cardinaletti \& Starke's (1999:156) observation that semantically vacuous pronouns (e.g. expletives and 'weather $i t$ ') are always weak.

To be concrete, the core prediction that we derive from a Percus \& Sauerland type system is the following. In order to derive a de se $L F$ such as (37b) (repeated from (6)), the pronoun can only contain semantically vacuous projections, as in (38a) (which corresponds to (33b)), and it cannot contain interpreted material, as in (38b) (which corresponds to (33a)). Similarly, due to Minimize DP!, it cannot contain superfluous structure, as in (38c) (which corresponds to (35b)).

(37) Percus \& Sauerland (2003b) style de se LF (for a dream report)

a. John dreams (that) he $\mathbf{e}_{\text {de se }}$ is tall.

b. de se LF: John dreams (that) he* $\lambda_{1}\left[\mathbf{t}_{\mathbf{1}}\right.$ is tall].

(38) a. possible morpho-syntax:

John dreams (that) $[\phi \mathrm{P} \phi]$ is tall.

b. impossible morpho-syntax 1 (ruled out by requirement for semantic vacuity):

John dreams (that) $\left[\phi \mathrm{P} \phi\left[\operatorname{DdetP} \mathrm{D}_{\operatorname{det}}[\mathrm{NP} \varnothing]\right]\right]$ is tall.

c. impossible morpho-syntax 2 (ruled out by Minimize DP!):

John dreams (that) $\left[\Sigma_{\mathrm{P}} \Sigma[\phi \mathrm{P} \phi]\right]$ is tall. 
In sections 3.2 and 3.3, I show that this prediction is borne out. In (Austrian) Bavarian ${ }^{9}$, we find a clear asymmetry between clitic pronouns (which prefer a de se interpretation) and non-clitic personal pronouns (which prefer a de re interpretation); in Kutchi Gujarati, the same asymmetry can be observed between null pronouns (which typically have to be read de se) and overt pronouns (which cannot be read de se). Both observations instantiate the expected contrast between (38a) (clitic/null) and (38c) (non-clitic/overt). These observations thus shed new light on the debate concerning the de se vs. de re distinction that I outlined in section 2 , in that they support a view that assumes dedicated de se LFs (containing uninterpreted de se pronouns) in addition to de re LFs (containing semantically interpreted de re pronouns).

Note that my proposal (in particular, its incorporation of Minimize DP!, (36)) provides a missing piece to Percus \& Sauerland's $(2003 a, b)$ ground-breaking work. I am grateful to an anonymous reviewer for pointing this out to me, whose suggested argumentation I lay out in the remainder of this section. Recall that Percus \& Sauerland argue that (39c) (repeated from (14b)) is not an available reading of the sentence in (39b) (repeated from (12b)); they attribute this to a syntactic "Attract Closest" constraint on the movement of de se pronouns (their Oneiric Reference Constraint). Crucially, however, the deviance of (39c) only follows if dedicated de se LFs (requiring the movement of uninterpreted de se pronouns) were the only way to produce de se readings. As discussed in the prose around (9)-(10), Percus \& Sauerland do not, in fact, rule out the possibility that de se readings can also arise from a de re pronoun with a selfacquaintance relation. Therefore, (39c) should in fact be an available interpretation of (39b) as long as both pronouns are construed de re (with two different acquaintance relations, the second being the de se inducing self-acquaintance relation); for Percus \& Sauerland, an additional mechanism is needed in order to block such a construal.

(39) a. Last night Pooh dreamed that he was Piglet.

b. Pooh dreamed that he was stealing his honey.

c.\# Pooh dreamed that $\mathbf{P o o h}(=$ de re $)$ was stealing Piglet's(=de se) honey. (adapted from Pearson \& Dery 2014)

The present paper supplies this missing mechanism in the form of Minimize DP!, as stated in (36). As shown earlier, in (8b) and (9b), de re pronouns are generally assumed to map to a covert resP structure. The structure of de re pronouns must thus always be more complex than the structure of dedicated de se pronouns, even if the acquaintance relation is a (de-se-reading inducing) self-acquaintance relation. Therefore, Minimize DP! will militate against deriving a de se reading from de re + self-acquaintance unless one of the conditions in (36ii) (Referential Irrelevance) or (36iii) (Pragmatic Irrelevance) is suspended. This correctly predicts that deriving de se from de re + self-acquaintance becomes available in the scope of only, as in (40), repeated from (10b), where (36ii) can be taken to be suspended: this is the same type of context in which other DP-related constraints such as Condition B are suspended, as shown by the acceptable (41a), which does not have the same denotation as (41b), cf. Reinhart (1983:169).

(40) Only John thinks he'll win the election.

(41) a. Only I will vote for me.

9 Standard German brings additional complexities due to homophonous weak vs. strong personal pronouns (Cardinaletti \& Starke 1999), which makes it more difficult to control for weakness in the sense that is required here. 
b. Only I will vote for myself.

After this brief comment on the benefits of Minimize DP! for a model based on Percus \& Sauerland (2003a,b), we can now proceed by showing the interplay between morphosyntax and semantics in more detail in sections 3.2 and 3.3.

\subsection{Dream reports and pronominal classes}

\subsubsection{Dream reports with intransitive verbs in Austrian Bavarian and Kutchi Gujarati}

In this section I provide data from Austrian Bavarian and Kutchi Gujarati, which confirm the prediction outlined in 3.1. Recall the core idea, that semantically vacuous pronouns are predicted to be structurally weak, which includes de se pronouns if Percus \& Sauerland are on the right track. The Austrian Bavarian examples in (42) (repeated from (28)) differentiate between clitic personal, strong personal and demonstrative pronominal paradigms. If de se correlates with the weakest possible form, we make the prediction that de se pronouns should be recruited from the class of clitic pronouns. This prediction is illustrated in Figure 4; the parallel prediction for Kutchi Gujarati is given in Figure 5, based on the comparison and discussion in section 3.1.
a. clitic personal das'a kummt.
b. strong personal das ea kummt. that $=$ he $_{\mathrm{CL}}$ comes that he comes 'that he comes'
c. demonstrative das dea kummt. that DEM comes 'that he comes'

Figure 4: prediction for (Austrian) Bavarian

null pronoun / $\frac{\text { clitic personal pronoun }}{\checkmark \text { DE SE }}$

Figure 5: prediction for Kutchi Gujarati

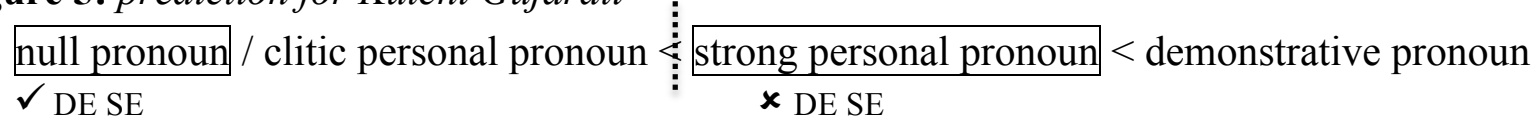

In what follows, I first focus on dream reports, since contexts like (43) (adapted from (12)) are more accessible to native speakers' intuitions than the mistaken identity contexts that are typically constructed for de re belief reports (see (1b), and section 3.2); we can expect that this will bring out contrasts more clearly. (See also Pearson \& Dery 2014.)

(43) a. Last night, I dreamed that I was my neighbour.

b. And I dreamed that I was rich.

c. de se referent $=$ 'the dream-self' = the speaker's neighbour

d. de re referent $=$ 'the dreamer' $=$ the speaker 
Setting up contexts such as the context with Pooh the bear that I discussed above (see (12)), it turns out that Bavarian exhibits a preference to use the clitic form for de se readings and the strong form for non-de se readings. ${ }^{10}$

Let us start with first person pronouns, for which the relevant forms are given in (44) (cf. Weiß 1998:87).

\begin{tabular}{|c|c|c|c|}
\hline & NOM ('I') & DAT ('to me') & $\mathrm{ACC}$ ('me') \\
\hline & $i[\mathrm{i}: \mathrm{I}]$ & $\operatorname{mia}[\mathrm{mi}: \mathrm{e}]$ & $m i[\mathrm{mi} \mathrm{l}]$ \\
\hline
\end{tabular}

Turning to dream reports, the clitic form can be shown to prefer a de se reading (in the bracketed clause), (45a), whereas the full form prefers a de re reading, (45b). Recall, as given in (43), that the de se referent of a dream report is the individual inside the dream that the dreamer identifies with, (43c), and not the actual dreamer; by contrast, the actual dreamer serves as the de re referent, (43d). The preferred readings of (45a) and (45b) are indicated.

(45) a. clitic pronoun (preference for de se reading)

I håb traamt, das 'e/i mei Nåchba bin und [das'e reich bin]. I have dreamed that $\mathrm{I}_{\mathrm{CL}} / \mathrm{I}_{\mathrm{FULL}}$ my neighbour am and that $=\mathrm{I}_{\mathrm{CL}}$ rich am 'I dreamed that I am my neighbour and that $\mathbf{I}_{\mathbf{C L}}\left(=\mathbf{m y}_{\text {neighbour }} \mathbf{d e ~ s e}_{\text {) }}\right.$ am rich.'

b. strong pronoun (preference for de re reading)

I håb traamt, das 'e/i mei Nåchba bin und [ das i reich bin]. I have dreamed that $\mathrm{I}_{\mathrm{CL}} / \mathrm{I}_{\mathrm{FULL}}$ my neighbour am and that $\mathrm{I}_{\mathrm{FULL}}$ rich am 'I dreamed that I am my neighbour and that $\mathbf{I}_{\text {FULL }}$ (= actual speaker $_{\text {de re }}$ ) am rich.'

It is plausible that the tendencies that I report reflect preferences rather than rigid constraints. In this vein, we also observe that the de se / de re preferences in (45) are limited to the second conjunct ('and that I was rich'). In the first conjunct ('that I was my neighbour'), the full pronoun $i$ and the clitic pronoun $e$ seem to be in free variation; this is plausibly due to the fact that it contains an identity statement. Presumably, the dreamer - let's call her Sue - does not realize that she is dreaming; so for Sue to dream that her dream-self is Sue's neighbor vs. to dream that Sue is, in fact, Sue's neighbor, may well describe different situations, but it is unclear in which exact respects they differ. ${ }^{11}$ Example (46) makes this explicit by showing what the respective readings are; (46a) is the unsurprising reading that we expect to correlate with the clitic pronoun $e$. If the dream self is, in fact, Bill, then (46a) amounts to the kind of statement that we make when we introduce ourselves by saying "I am Bill." or when we introduce a friend of ours by saying "This is Bill." By contrast, (46b) is the more surprising reading that we expect to correlate with the non-clitic pronoun $i$. Presumably, (46b) describes a situation in which Sue reports a dream in which Sue, the dreamer, identifies with Bill. Intuitively, she does not dream of a situation in which Sue and Bill are, in fact, one and the same person in different guises, either in the real

\footnotetext{
${ }^{10}$ Note, of course, that this discussion raises an issue addressed by Anand (2006) and Pearson \& Dery (2014), namely the question of whether belief-reports and dream-reports behave on a par when it comes to the observed patterns. One possible conclusion from the differences that I discuss in section 3.3 of this paper (compatible with the previous literature) is that de se readings in dream-reports require Percus \& Sauerland style pronoun movement whereas de se readings in belief-reports do not.

${ }^{11}$ Note that there is also a question of whether focus is a confound in (45b). I come back to this question later.
} 
world or in Sue's dream worlds (this does not seem to be the intended reading). It is beyond the scope of this paper to formalize the semantics that underlies (46b) (which plausibly involves access to individuals across possible worlds), though this seems to be intuitively on the right track.

\section{(46) Sue is dreaming.}

a. de se context: In this dream, the 'narrative I' is Sue's neighbor, Bill.

Sue dreams that $\mathbf{s h e}_{\text {de se }}$ (= the dream self) is Bill.

b. (non-de se) de re context: In this dream, the 'narrative I' is Sue's neighbor, Bill.

Sue dreams that she de $_{\text {re }}$ (= Sue's self in the real world) is Bill.

Of course, in the second conjuncts of (45a) and (45b) (which do not contain an identity statement), it has already been established that the dream-self is Sue's neighbor and Sue (as the dreamer) is the dream-self's neighbor, giving rise to clearly distinct truth conditions for the de se vs. $d e$ re readings. For simplification, I will only provide the clitic variant ' $e$ in the first conjunct of subsequent examples.

What is crucial is that exactly the same pattern arises for Kutchi Gujarati null vs. overt pronouns (also with respect to the first conjunct), as given in (47), indicating that the pattern in (45) is a more robust cross-linguistic observation, rather than a Bavarian oddity.

(47) a. null pronoun (preference for de se reading)

$\begin{array}{llllll}\text { Mane } & \text { sapnu aavyu } \quad \text { ke hu/pro maro parosi chu } \\ \text { 1.sg.dat } & \text { dream came.pfv.n.sg that } & 1 . \text { sg.nom } & \text { my.m.sg } & \text { neighbour is.1.sg.pres } \\ \text { ane pro } & \text { paisadar manas chu. } & & & \\ \text { and } & \text { wealthy man is.1.sg.pres } & & \end{array}$

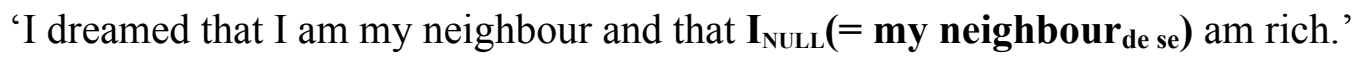

b. overt pronoun (preference for de re reading)

$\begin{array}{llllll}\text { Mane } & \text { sapnu aavyu } & \text { ke hu/pro maro } & \text { parosi chu } \\ \text { 1.sg.dat } & \text { dream came.pfv.n.sg that } & 1 . s g . n o m & \text { my.m.sg } & \text { neighbour is.1.sg.pres } \\ \text { ane hu paisadar manas chu. } & & & \\ \text { and 1.sg } & \text { wealthy man is.1.sg.pres }\end{array}$

'I dreamed that I am my neighbour and that $\mathbf{I}_{\text {OVERT }}\left(=\right.$ actual speaker $\left._{\text {de re }}\right)$ am rich.'

We can thus summarize the pattern in (45) as in Figure 6a (repeated from Figure 4), though the reader should bear in mind that we may well be speaking of preferences, and not of rigid constraints. Similarly, the pattern in (47) further supports the generalization in Figure $6 \mathrm{~b}$ (repeated from Figure 5).

Figure 6a: clitic-vs-full languages (Bavarian)

null pronoun / $\frac{\text { clitic personal pronoun }}{\checkmark \text { DE SE }}$ strong personal pronoun $<$ demonstrative pronoun 
Figure 6b: null-vs-overt languages (Kutchi,Gujarati)

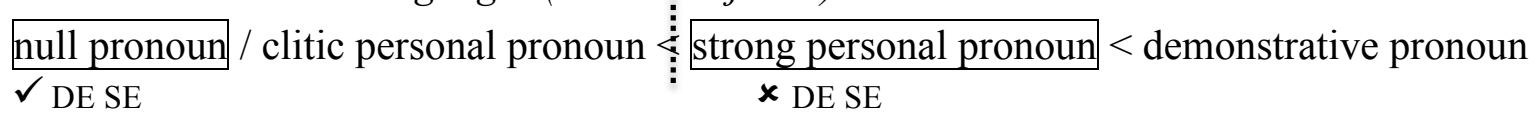

The generalizations in Figure $6 \mathrm{a}$ and Figure $6 \mathrm{~b}$ are exactly what we would expect from a Percus \& Sauerland $(2003 \mathrm{a}, \mathrm{b})$ perspective. The prediction that we derived from their account is that de se pronouns must remain uninterpreted. Naturally, the most minimal pronoun is the most likely pronoun to be uninterpreted, since it lacks surplus structure that either has a semantic effect or violates structural eoconomy (in the spirit of Minimize DP!).

At this point, there is one more issue that needs to be addressed. So far, I have focused on the generalization that strong pronouns cannot be read de se. The explanation for this generalization may be (in some cases) that the strong pronoun contains interpretable functional material, or (in other cases) that the strong pronoun is uneconomical in line with constraints such as Minimize $D P !$, repeated in (48) from (36).

\section{(48) Minimize DP!}

An extended NP projection $\alpha$ is deviant if $\alpha$ contains redundant structure, i.e. if

(i) there is an extended NP projection $\beta$ that contains less syntactic nodes than $\alpha$,

(ii) $\beta$ is grammatical and has the same denotation as $\alpha$ (= Referential Irrelevance), and

(iii) using $\alpha$ instead of $\beta$ does not serve another purpose (= Pragmatic Irrelevance)

However, this raises a question of why strong pronouns can have a de re reading, as given in (49), repeated from (45b). This is puzzling, since a de re LF is presumably compatible with both a strong (non-clitic) pronoun, (35a), and a weak (clitic) pronoun, (33a), as long as both are interpreted (and plausibly incorporate the covert resP structure assumed in Percus \& Sauerland 2003a, Anand 2006, Pearson 2015, which I omit here for simplification) ${ }^{12}$. Minimize DP! should thus block strong pronouns in such contexts as well.

\section{strong pronoun (preference for de re reading)}

I håb traamt, das 'e/i mei Nåchba bin und [ das $\mathbf{i}$ reich bin].

I have dreamed that $\mathrm{I}_{\mathrm{CL}} / \mathrm{I}_{\mathrm{FULL}}$ my neighbour am and that $\mathrm{I}_{\mathrm{FULL}}$ rich am

'I dreamed that I am my neighbour and that $\mathbf{I}_{\mathbf{F U L L}}\left(=\right.$ actual $_{\text {speaker }}$ de re) $_{\text {) }}$ am rich.'

Glossing over the $1^{\text {st }}$ vs. $3^{\text {rd }}$ person distinction (see also section 3.2.2, in particular examples (67) and (68)), this problem can be illustrated for (50), repeated from (7). In line with what we know, (51b) (which incorporates the structure of an interpreted clitic pronoun in (33a)) should be equally acceptable as (51a) (which incorporates the structure of an interpreted non-clitic pronoun in (35a)). As a consequence, (51a) should be blocked by Minimize DP! in favor of the more economic (51b), and de re readings should also require the clitic pronoun. This is the opposite of what we find.

(50) a. John dreams (that) $\mathbf{h e}_{\text {de re }}$ is tall.

b. de re LF (simplified): John dreams PROP he $\mathbf{2}_{2}$ is tall. where $\mathrm{g}=[2 \rightarrow \mathrm{John}]$

\footnotetext{
${ }^{12}$ It is not an aim of this paper to map out how exactly such covert LF material (i.e., the res $P$ ) is mapped, e.g., to the pronoun-internal NP of (33a) and (35a).
} 
(51) a. attested (non-clitic) morpho-syntax:

John dreams (that) $\left[\Sigma_{\mathrm{P}} \Sigma\left[\phi_{\mathrm{P}} \phi\left[\operatorname{DdetP} \mathrm{D}_{\mathrm{det}}[\mathrm{NP} \varnothing]\right]\right]\right]$ is tall.

b. unattested (clitic) morpho-syntax:

John dreams (that) $\left[\phi P \phi\left[\operatorname{DdetP} D_{\operatorname{det}}[\mathrm{NP} \varnothing]\right]\right]$ is tall.

Let us recapitulate the facts. We have established that strong pronouns exhibit a restriction against being interpreted de se, (52a), due to their additional functional structure; by contrast, weak pronouns can be interpreted de se, but there is nothing (so far) that blocks them from being interpreted de re, (52b). As a consequence, we expect that strong pronouns are also banned from being interpreted de re (as Minimize DP! should rule out this use as well), giving rise to the pattern in (53); but we find the pattern in (54) instead of the pattern in (53).

(52) established in the discussion so far

a. strong pronoun: ${ }^{\mathrm{OK}}$ de re / \#de se

b. weak pronoun: ${ }^{\mathrm{OK}}$ de re $/{ }^{\mathrm{OK}}$ de se

(53) predicted (due to Minimize DP!)

a. strong pronoun: \#de re / \#de se

b. weak pronoun: ${ }^{\mathrm{OK}}$ de re $/{ }^{\mathrm{OK}} \mathrm{de}$ se

(54) attested

a. strong pronoun: ${ }^{\mathrm{OK}}$ de re / \#de se

b. weak pronoun: \#de re $/{ }^{\mathrm{OK}}$ de se

The idea that I pursue (inspired by Chomsky 1981:65) is that the very competition between strong pronouns and weak pronouns in (52a-b) pragmatically blocks a de re use of weak pronouns. The rationale that I pursue is based on an intuitive asymmetry between de se and de re readings in terms of markedness, in the sense that de se readings seem to be unmarked and de re readings marked; this can be fleshed out as follows. Reconsider the pair of sentences in (55), adapted from (45); again, we are concerned with the bold-typed pronoun in the second conjunct. For this bold-typed pronoun, a speaker can either have a de re intention (= 'that the actual speaker is rich [in the dream]') or a de se intention (= 'that the actual speaker's neighbor is rich [in the dream]'). In the spirit of Percus \& Sauerland (2003b), a de se variant is derived by leaving the bold-typed pronoun uninterpreted and moving it to the left-periphery to generate a de se LF. As discussed in the literature, de re readings tend to be more marked and harder to access than de se readings (cf. Pearson \& Dery 2014, amongst many others). As discussed by Patel-Grosz \& Grosz (2017:279-288), the various pragmatic effects that license strong(er) pronouns in line with (48-iii) are still not fully understood, but they are often tied to a speaker's intention to make a less salient (or more marked) reading accessible. The attested pattern in (54) can thus be explained as follows: strong pronouns with a de re reading serve to flag a marked reading, which is a pragmatic effect in line with (48-iii), and this is why they are not blocked by Minimize DP!.

(55) a. weak (clitic) pronoun (preference for de se reading, which is unmarked)

I håb traamt, das'e mei Nåchba bin und [das'e reich bin]. I have dreamed that $=\mathrm{I}_{\mathrm{CL}}$ my neighbour am and that $=\mathrm{I}_{\mathrm{CL}}$ rich am 'I dreamed that I am my neighbour and that $\mathbf{I}_{\mathbf{C L}}$ am rich.' 
b. strong (full) pronoun (preference for de re reading, which is marked)

I håb traamt, das'e mei Nåchba bin und [ das i
I have dreamed that $=\mathrm{I}_{\mathrm{CL}}$ my neighbour am and that $\mathrm{I}_{\mathrm{FULL}}$ rich am
'I dreamed that I am my neighbour and that $\mathbf{I}_{\mathbf{F U L L}}$ am rich.'

Correspondingly, my proposal for the missing de re interpretation of (55a) is as follows. As discussed, example (55b) admits for a de re reading in line with Minimize DP! due to pragmatic relevance, whereas the unmarked de se reading is excluded for the strong pronoun $i$. As a direct consequence, (55b) is unambiguously de re, whereas (55a) is ambiguous between a de se reading and a de re reading; this is the point of departure, as given in (52). If we now turn to a scenario in which the speaker intends a de re LF, then we can ask how she chooses between (55a) and (55b). If she chooses (55a), the sentence will be ambiguous (as it also allows for a de se LF); by contrast, if she chooses (55b), the sentence will no longer be ambiguous. On the level of pragmatics, a speaker thus has a choice between an ambiguous weak pronoun, (52b), and an unambiguously de re strong pronoun, (52a). Using a strong pronoun would be more informative, given that it would resolve the de se / de re ambiguity. We thus expect that it is inferred at the level of implicature (much in line with how scalar implicatures come about) that a de se LF is intended for the weak pronoun, (52b), simply because the speaker has chosen not to use the strong pronoun. ${ }^{13}$ This gives rise to the eventual interpretation pattern in $(54 a-b)$.

After having discussed the relevant patterns with embedded intransitive predicates in this section, I now proceed to discuss transitive predicates as well. In the next section, I focus on dream reports that contain two embedded pronouns, to revisit the empirical observations from the literature, discussed in sections 2.3, and to see if Austrian Bavarian and Kutchi Gujarati exhibit superiority effects in the spirit of Percus \& Sauerland (2003b). In this section, I show that the Bavarian and Kutchi Gujarati counterparts further corroborate a view where there are distinct de se LFs in the spirit of Percus \& Sauerland (2003a,b). I also take a closer look at potential interactions between pronominal strength and focus.

\subsubsection{Dream reports with transitive verbs and the superiority question}

First of all, the observation that Bavarian clitic pronouns have a de se preference while non-clitic pronouns have a de re preference extends to transitive predicates with a nominative and a dative argument. Consider first the de se + de re case (using the labels from Pearson \& Dery 2014 introduced above), given in (56b). As expected, if the subject is a clitic pronoun ( $(e$ ' $\mathrm{I}$ ') and the object is a full pronoun (mia 'me'), then the subject is interpreted de se and the object is interpreted $d e$ re. This reproduces the pattern in section 3.2.1, i.e. the clitic/full contrast correlates with a de se/de re contrast. It thus further corroborates the main empirical claim made in this paper.

(56) a. I håb traamt, das'e da Batman bin.

I have dreamed that $=I_{C L}$ the Batman am

'I dreamed that I was Batman.' [de se Batman, de re actual speaker]

\footnotetext{
${ }^{13}$ An anonymous reviewer raises the question of whether this means that the use of a weak pronoun implicates the lack of a de re belief, i.e. whether I believed that I(weak) was rich would implicate that the speaker did not have a de $r e$ belief about the speaker being rich. This is not, strictly speaking, what I am arguing here. My proposal solely amounts to the idea that I believed that I(weak) was rich implicates that the speaker intends to use a designated de se $L F$.
} 

b. Und i håb traamt, das'e mia ghuifn håb. [de se subject/de re object] and I have dreamed that $=\mathrm{I}_{\mathrm{CL}}$ me $\mathrm{FULL}$ helped have
'And I dreamed that $\mathbf{I}_{\mathbf{C L}}\left(=\right.$ Batman $\left._{\text {de se }}\right)$ helped $\mathbf{m e}_{\mathbf{F U L L}}\left(=\right.$ actual speaker $\left._{\mathrm{de} \text { re }}\right)$.'

Having argued in sections 3.2.1 that the distribution of weak vs. strong pronouns supports the Percus \& Sauerland approach to de se vs. de re readings, we can now ask whether examples with more than one pronoun also exhibit "superiority" effects as discussed in section 2.3; as we will see, such superiority effects seem to be absent in Bavarian, which initially may appear to be puzzling, but it plausibly follows from the pronominal system of Bavarian and from scrambling as a process that can target pronouns independently from, say, de-se-related movement (see also Wiltschko 1997).

Recall that "superiority" has been argued to rule out configurations in which a structurally higher element (such as a transitive subject) is read de re and a c-commanded element (such as a transitive object) is read de se, see (11)-(16). Interestingly, if (in the same context as (56)) the subject is a full pronoun ( $i$ 'I') and the object is a clitic pronoun ( $m a$ ' $m e^{\prime}$ '), as in (57), we find that the clitic object pronoun also prefers a de se construal, whereas the non-clitic subject pronoun prefers a de re reading. This may strike us as surprising at first, since this corresponds to the de re + de se reading that has been claimed to be unacceptable (due to "superiority"), see (14b) above. However, it is fully compatible with an explanation in terms of Percus \& Sauerland (2003a,b): in their system, the superiority constraint that blocks a de re + de se reading is featurebased, i.e. a de se pronoun cannot be c-commanded by a feature-identical de re pronoun. Since full pronouns contain prosodic features (encoded in a $\Sigma$ P), which clitic pronouns lack, cf. (29), this alone may explain why Bavarian pronouns obviate superiority. Moreover, the unmarked word order in (57) is one where the clitic $m a$ 'me' has moved across the non-clitic $i$ ' $\mathrm{I}$ ' to a position adjacent to the complementizer, thus reversing the c-command relationship between the de se pronoun $m a$ 'me' and the de re pronoun $i$ ' $\mathrm{I}$ '. This clitic movement can be seen as a type of scrambling, which in turn has been shown to interact with superiority (see Wiltschko 1997). Given that superiority is assumed to be a syntactic constraint, it thus follows that (57) should obviate superiority for this reading as well (as long as clitic movement is a syntactic operation as well, cf. Cardinaletti \& Starke 1999; if clitic movement in a language such as Bavarian were a PF operation, this explanation may have to be revisited).

(57) Und i håb traamt, das'ma i ghuifn håb. [de re subject/de se object] and I have dreamed that $=$ me $_{\mathrm{CL}} \mathrm{I}_{\mathrm{FULL}}$ helped have 'And I dreamed that $\mathbf{I}_{\mathbf{F U L L}}\left(=\right.$ actual $_{\text {speaker }_{\text {de re }}}$ ) helped $\mathbf{m e}_{\mathbf{C L}}\left(=\right.$ Batman $\left._{\text {de se }}\right)$.'

Interestingly, if the clitic pronoun cliticizes to the non-clitic pronoun, as in (58), which is an alternative word order in Austrian German, speakers report that the intended de re + de se reading becomes less acceptable, and the sentence becomes deviant. Since (58) was an example with much interspeaker variation, I mark its limited acceptability with '\%”.

(58)\% Und i håb traamt, das i’ma ghuifn håb. [de re subject/de se object] and I have dreamed that $\mathrm{I}_{\mathrm{FULL}}=\mathrm{me}_{\mathrm{CL}}$ helped have 'And I dreamed that $\mathbf{I}_{\text {FuLL }}\left(=\right.$ actual speaker $\left._{\text {de re }}\right)$ helped me $_{\mathbf{C L}}\left(=\right.$ Batman $_{\text {de se).' }}$ ' 
Notably, the exact same patterns arise for Kutchi Gujarati null vs. overt pronouns. Example (59) is parallel to (56) and gives rise to the de se + de re reading. As indicated, the null pronoun is construed de se, whereas the overt pronoun is construed de re.
a. Mane sapnu aavyu ke pro Batman hathi. 1.sg.dat dream.n.sg come.pfv.n.sg that Batman was
'I dreamed that I was Batman.' [de se Batman, de re actual speaker]
b. Ane mara sapna-ma pro mane madath kari [de se subject/de re object] and 1.sg.gen dream-in 1.sg-acc help do.pfv.f.sg
'And I dreamed that $\mathbf{I}_{\text {NULL }}\left(=\right.$ Batman $\left._{\text {de se }}\right)$ helped me $_{\text {ovERT }}\left(=\right.$ actual speaker $\left._{\text {de re }}\right)$.'

Similarly, (60) is parallel to the Bavarian example (57), giving rise to the de re + de se reading. The observation that (60) does not violate superiority indicates that null pronouns, on a par with clitic pronouns, lack feature identity with full (overt) pronouns and/or must move to a position above the overt pronouns, thus reversing the c-command relation between them.
a. Mane sapnu aavyu ke pro Batman hathi.
1.sg.dat dream.n.sg come.pfv.n.sg that Batman was
'I dreamed that I was Batman.' [de se Batman, de re actual speaker]
b. Ane mara sapna-ma i pro madath kari [de re subject/de se object] and 1.sg.gen dream-in 1.sg.nom help do.pfv.f.sg
'And I dreamed that $\mathbf{I}_{\text {OVERT }}\left(=\right.$ actual speaker $\left._{\text {de re }}\right)$ helped $\mathbf{m e}_{\text {NULL }}\left(=\right.$ Batman $_{\text {de se }}$ )'

It is worth discussing a potential concern at this point, namely the role of focus as a potential confound for pronominal strength. An anonymous reviewer points out that strong pronouns might always be carrying focus stress (possibly contrastive focus; see also Cardinaletti \& Starke 1999:161-162). For examples (56b) and (57), this can be made explicit as in (61). If this were the case, the fact that the full pronoun refers to the dreamer (and not to the dream-self) may simply follow from focus interpretation, as focus flags intended reference to an individual that is not the most salient. On a related note, we may wonder if de se pronouns could ever be focused; in fact, since clitics cannot carry focus stress, an anonymous reviewer points out that focus on a de se pronoun may be expected to give rise to a situation where a stronger pronoun (that can be focused) can be read de se. This follows, as the choice of a stronger pronoun would give rise to a pragmatic effect in the spirit of Minimize DP! However, since focus of the relevant type serves to generate semantic alternatives (i.e. \{Batman helped me, Batman helped Greg, Batman helped Sue, ... \}; see Rooth 1985, 1992; see Krifka 2008 for a representative overview article on the topic), this presupposes that the focused pronoun has a semantic interpretation, thus precluding an uninterpreted de se pronoun in the spirit of a de se LF as proposed by Percus \& Sauerland (2003b).

(61) a. Und i håb traamt, das'e [ MIA $]_{\mathrm{F}}$ ghuifn håb. [de se subject/de re object] and I have dreamed that $=\mathrm{I}_{\mathrm{CL}}$ me $_{\mathrm{FULL}}$ helped have

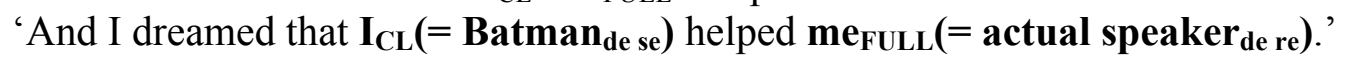

b. Und i håb traamt, das'ma $[\mathbf{I}]_{\mathrm{F}}$ ghuifn håb. [de re subject/de se object] and I have dreamed that $=\mathrm{me}_{\mathrm{CL}} \mathrm{I}_{\mathrm{FULL}}$ helped have

'And I dreamed that $\mathbf{I}_{\mathrm{FULL}}\left(=\operatorname{actual}_{\text {speaker }}\right.$ de re $)$ helped $\mathbf{m e}_{\mathrm{CL}}\left(=\right.$ Batman $\left._{\mathrm{de}} \mathrm{se}\right)$.' 
However, even if we control for focus by introducing predicates that are natural when focused, the de se / de re preferences stay the same, as illustrated in (62); in (62a) the verb is (emphatically) focused, while in (62b) the direct object carries emphatic focus. In both cases, mia can be deaccented and still retains a de re preference.

(62) a. Und i håb traamt, das'e mia [ NOCHgrennt $]_{\mathrm{F}}$ bin. and I have dreamed that $=\mathrm{I}_{\mathrm{CL}}$ me $_{\mathrm{FULL}}$ ran.after am

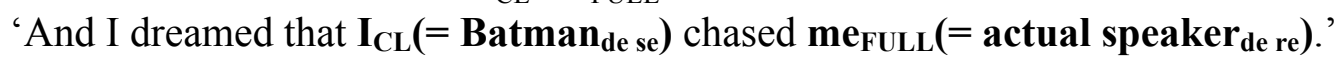

b. Und i håb traamt, das'e mia [ GUID $]_{\mathrm{F}}$ gschenkt håb. and I have dreamed that $=\mathrm{I}_{\mathrm{CL}} \mathrm{me}_{\mathrm{FULL}}$ gold gifted have

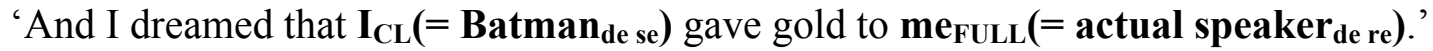

Again, if we swap the clitic/full realization of the subject and object pronouns, the de se/de re preference inverts accordingly, as shown in (63). (Note that here, the order $i<$ ' $m a$ is preferred over the order ' $m a<i$, as opposed to what we saw in (57) and (58).)
a. Und i håb traamt, das i'ma
[ NOCHgrennt $]_{F}$ bin.
and I have dreamed that $\mathrm{I}_{\mathrm{FULL}}=\mathrm{me}_{\mathrm{CL}}$ ran.after
am

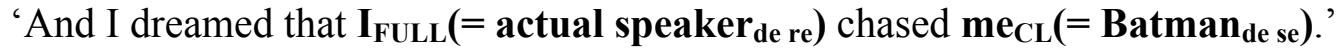
b. Und i håb traamt, das i'ma [GUID $]_{\mathrm{F}}$ gschenkt håb.
and I have dreamed that $\mathrm{I}_{\mathrm{FULL}}=\mathrm{me}_{\mathrm{CL}}$ gold gifted have
'And I dreamed that $\mathbf{I}_{\mathrm{FULL}}\left(=\right.$ actual speaker $\left._{\mathrm{de} \text { re }}\right)$ gave gold to $\mathbf{m e}_{\mathrm{CL}}\left(=\right.$ Batman $\left._{\mathrm{de}} \mathrm{se}\right)$.'

Furthermore, if two identical (non- $3^{\text {rd }}$-person) pronouns co-occur in Bavarian, the resulting reading is typically reflexive. (Bavarian, like Standard German, does not have dedicated $1^{\text {st }}$ or $2^{\text {nd }}$ person reflexives, i.e. ma/mia are ambiguous between 'me' and 'myself'). However, again, the class of pronoun determins whether reference is de se, (64b), or de re, (64c).

(64) a. I håb traamt, das'e da Batman bin.

I have dreamed that $=\mathrm{I}_{\mathrm{CL}}$ the Batman am

'I dreamed that I was Batman.' [de se Batman, de re actual speaker]

b. Und i håb traamt, das'e'ma ghuifn håb. [de se subject/de se object] and I have dreamed that $=\mathrm{I}_{\mathrm{CL}}=\mathrm{me}_{\mathrm{CL}}$ helped have

'And I dreamed that $\mathbf{I}\left(=\right.$ Batman $\left._{\text {de se }}\right)$ helped myself(= Batman $\left._{\text {de se }}\right)$.'

c. Und i håb traamt, das i mia ghuifn håb. [de re subject/de re object] and I have dreamed that $\mathrm{I}_{\mathrm{FULL}}$ me $\mathrm{FULL}$ helped have

'And I dreamed that $\mathbf{I}\left(=\right.$ actual speaker $\left._{\text {de re }}\right)$ helped myself(= actual speaker $_{\text {de re }}$ ).'

The same holds for Kutchi Gujarati (where first person and second person reflexives can also occur without reflexive marking, though they allow for reflexive marking to indicate emphasis), as shown in (65).

(65)
a. Mane sapnu aavyu ke pro Batman hathi.
1.sg-dat dream.n.sg come.pfv.n.sg that Batman was
'I dreamed that I was Batman.' [de se Batman, de re actual speaker] 
b. Ane mara sapna-ma pro pro madath kari [de se subject/de se object] and 1.sg.gen dream-in help do.pfv.f.sg

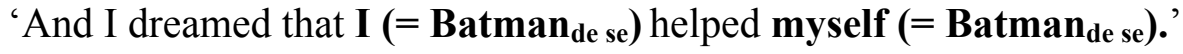

c. Ane mara sapna-ma hu mane madath kari [de re subject/de re object] and 1.sg.gen dream-in 1.sg.nom 1.sg-acc help do.pfv.f.sg

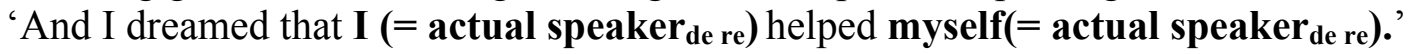

Finally, we can look at examples in which clitic pronouns are unacceptable, such as the complement of a preposition, which must be a full pronoun (in Bavarian: voa mia 'of me $\mathrm{FULL}$ ' vs. *voa $m a$ 'of me $_{\mathrm{CL}}$ '). Since the distribution of de re vs. de se readings is due to Minimize DP! and thus arises from competition between full and clitic pronouns, we predict that the relevant pronouns are ambiguous. This is an important prediction, as Minimize DP! only concerns competition between two pronouns that can otherwise both occur in the same environment. This is indeed what we find. (I thank an anonymous reviewer for pointing this out and for suggesting the following examples.) As indicated in (66a-b), the full pronoun mia is ambiguous between a de re pronoun and a de se pronoun. This is predicted by Minimize DP! (since a clitic pronoun would simply be ungrammatical here and no competition arises). If we introduce another full/clitic pronoun into the sentence, as in (66c-d), that additional pronoun exhibits a de se / de re preference again, as above, which is in line with Minimize DP! (Of course, the resulting readings are then constrained by plausibility, since a reading in which the actual speaker/batman is afraid of himself is implausible.)

(66) a. I håb traamt, das'e da Batman bin.

I have dreamed that $=\mathrm{I}_{\mathrm{CL}}$ the Batman am

'I dreamed that I was Batman.' [de se Batman, de re actual speaker]

b. Und ålle håm si [voa mia /*ma] gfiacht.

and all have self before me $\mathrm{FULL}_{\mathrm{L}} \mathrm{me}_{\mathrm{CL}}$ been.afraid

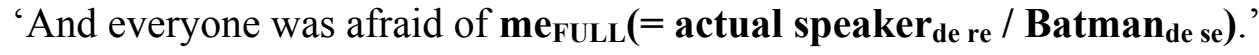

c. Und i håb mi [voa mia /*ma] gfiacht. and $\mathrm{I}_{\mathrm{FULL}}$ have self before me $\mathrm{FULL}_{\mathrm{F}} \mathrm{me}_{\mathrm{CL}}$ been.afraid

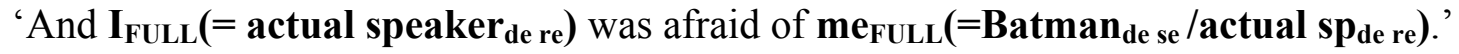

d. Und e håb mi [voa mia /* ma] gfiacht.

and $\mathrm{I}_{\mathrm{CL}}$ have self before me $\mathrm{FULL}_{\mathrm{FL}} \mathrm{me}_{\mathrm{CL}}$ been.afraid

'And $\mathbf{I}_{\mathbf{C L}}\left(=\right.$ Batman $\left._{\text {de se }}\right)$ was afraid of $\mathbf{m e}_{\mathrm{FULL}}\left(=\mathbf{a c t u a l}_{\text {speaker }}\right.$ de re $\left./ \mathbf{B a t m a n}_{\mathrm{de} \mathrm{se}}\right)$.'

Having shown that such judgments hold for the $1^{\text {st }}$ person, we can also observe that parallel judgments hold for the $3^{\text {rd }}$ person (here, the variants that are parallel to $(64 b-c)$ and $(65 b-c)$ are deviant, since a reflexive is required; I come back to this in the next section). Example (67) shows that the clitic pronoun prefers a de se reading, whereas the full pronoun prefers a de re reading.

(67) a. Da Joker håt traamt, das'a da Batman is.

the joker has dreamed that $=\mathrm{he}_{\mathrm{CL}}$ the Batman am

'The Joker dreamed that he was Batman.' [de se Batman, de re the Joker] 
b. Und ea håt traamt, das'a eam übafåin håt. [de se subject/de re object] and he has dreamed that $=\mathrm{I}_{\mathrm{CL}}$ me $\mathrm{FULL}_{\mathrm{F}}$ ambushed has

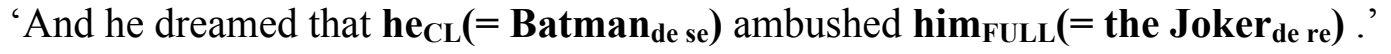

c. Und ea håt traamt, das'n ea übafåin håt. [de re subject/de se object] and he has dreamed that $=$ him $_{\mathrm{CL}}$ he $_{\mathrm{FULL}}$ ambushed has

'And he dreamed that $\mathbf{h e}_{\mathrm{FULL}}\left(=\right.$ the $\operatorname{Joker}_{\mathrm{de}}$ re $)$ ambushed $\mathbf{h i m}_{\mathrm{CL}}\left(=\operatorname{Batman}_{\mathrm{de} \mathrm{se}}\right)$.'

Once again, the exact same judgments hold in Kutchi Gujarati, as shown in (68).

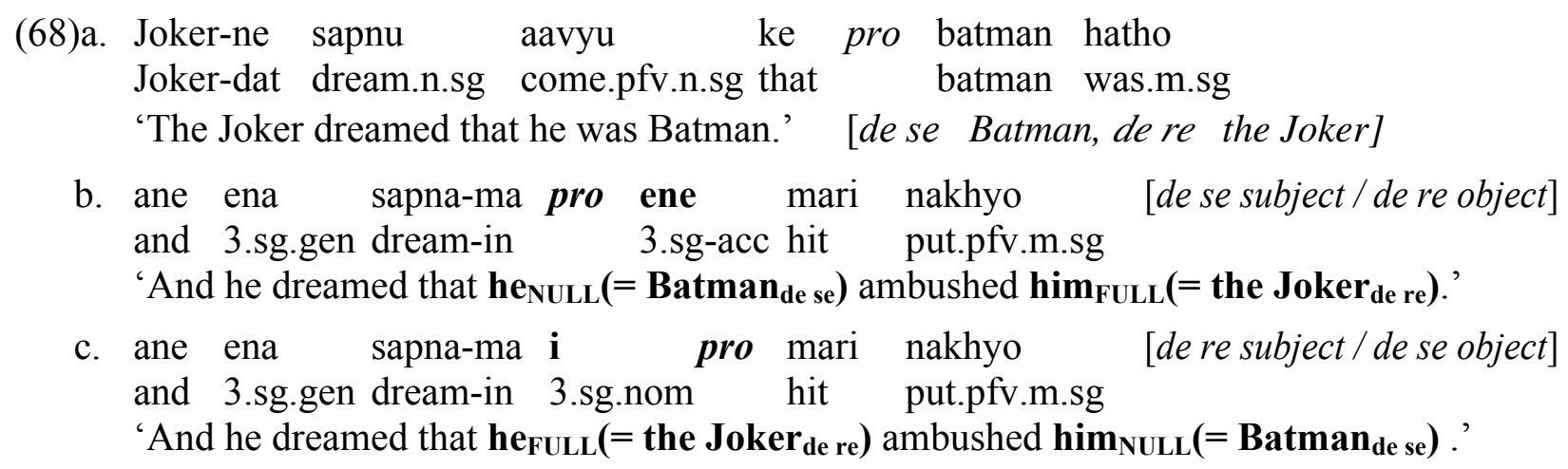

To sum up the results of this section, we have seen that the correlation between clitic/full pronouns and de se/de re preference in Austrian Bavarian, and the parallel correlation between null/overt pronouns and de se/de re preference in Kutchi Gujarati carries over to transitive examples with two pronouns.

\subsubsection{Interim summary}

Based on studying the behavior of different types of pronouns in dream reports, we arrive at the following conclusions. First, the fact that strong pronouns exhibit a de re preference and weak pronouns exhibit a de se preference fits the idea that de se pronouns are uninterpreted. If strong pronouns contain more structure than weak pronouns, the use of strong pronouns will generally be penalized by structural economy constraints (Minimize DP!). The distribution of weak vs. strong pronouns supports a view in which dedicated de se LFs are generated by virtue of the movement of uninterpreted de se pronouns (as in Percus \& Sauerland 2003a,b). By contrast, a view that treats all de se readings as a special type of de re interpretation without dedicated de se LFs (as in Reinhart 1990 and Maier 2009) can be adapted to derive this distribution, but not without further assumptions. Specifically, it needs to assume some asymmetry between non-de$s e$-inducing de re pronouns, in (69b) (adapted from (8b)), and de-se-inducing de re pronouns, in (69c) (adapted from (9b)), such that the latter correlate with structural deficiency.

(69) a. John believes that he is tall.

b. (non-de se) de re reading, modeled by means of a definite description

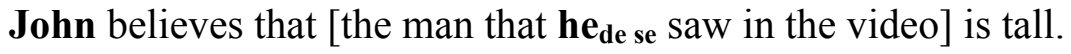

c. de se reading, modeled as de re + self-acquaintance

John believes that [the man that he $\mathbf{d e}_{\text {e se }}$ identifies with] is tall. 
Without such an additional assumption, approaches without uninterpreted de se pronouns do not immediately predict any correlation between pronominal weakness and de se preference.

In this section, I have also shown that Bavarian and Kutchi Gujarati lack superiority effects, and I have argued that this is compatible with a Percus \& Sauerland style pronoun movement analysis. On the one hand, clitic pronouns (and presumably null pronouns) must move to a position in which they c-command full pronouns in the clause (which I take to be a syntactic movement operation; cf. Cardinaletti \& Starke 1999); as a result, de se pronouns will always ccommand de re pronouns prior to their movement to the clausal left periphery. On the other hand, clitic/null pronouns and full pronouns are not feature identical and thus may not be subject to a feature-based "superiority" constraint to begin with. The relevant findings with regards to the strength hierarchy are repeated in Figures $7 \mathrm{a}$ and $7 \mathrm{~b}$.

$$
\begin{aligned}
& \text { Figure 7a: clitic- } v \text { s-full languages (Bavarian) } \\
& \text { null pronoun / } \\
& \begin{array}{c}
\text { clitic personal pronoun } \\
\checkmark \text { DE SE }
\end{array}
\end{aligned}
$$

Figure 7b: null-vs-overt languages (Kutchi,Gujarati)

null pronoun / clitic personal pronoun strong personal pronoun $<$ demonstrative pronoun $\checkmark$ DE SE $\quad \times$ DE SE

\subsection{Pronominal classes and belief reports}

\subsubsection{Kutchi Gujarati part I: overt pronouns cannot be read de se}

The diagnostics in this section test for de se construals with belief reports and further corroborate the findings from section 3.2. To argue for de se LFs, Percus \& Sauerland (2003a,b) originally construct contexts with attitude predicates, in which the salient attitude holders are quantified over; specifically, they use sentences that contain the exclusive focus particle only (Santorio 2014 thus calls this "the argument from only"). In (70) and (71), Percus \& Sauerland (2003a,b) construct a pair of context and test sentence, where the test sentence, (71), is false under any sensible de re reading (without self-ascription), but true under a specialized de se reading (with self-ascription). In other words, the expectation is that in the context given in (70), the example in (71) is true with a de se construal of he, whereas it is false with a de re construal of the pronoun. This follows from the facts, summarized in (72), where the only person with a selfattributed de se belief (i.e. "I will win") is Valji, (72c). If we were looking at beliefs that are not de se, Valji is not the only one who believes in his own victory, (72b), and he is not the only one who believes that Valji will win, (72a).

(70) Context: Drunk election candidates are watching campaign speeches on TV, and do not recognize themselves in the broadcast. Valji, the only confident one, thinks "I'll win," but does not recognize himself in the broadcast. Khimji and Raj, both depressive, think "I'll lose" but are impressed by the speeches that happen to be their own and are sure "that candidate" will win. Lalji, also depressive, happens to be impressed not by his own speech but by Valji's.

(adapted from Percus \& Sauerland 2003a)

(71) "Only Valji believes that he will win." 
a. people who believe that Valji will win $=\{$ Valji, Lalji $\}$

b. people who believe (de se or de re) that they themselves will win $=\{$ Valji, Khimji, Raj $\}$

c. people who believe de se that they themselves will win $=\{$ Valji $\}$

Percus \& Sauerland claim that (71) in English is judged to be true in the context in (70), i.e. a de se reading that picks out the set in $(72 \mathrm{c})$ must be available. In Kutchi Gujarati, both the translation with an overt pronoun $i$ 'he' in (73) and the translation with a null pronoun in (74) are grammatical (contrasting with (26) above, where we did not consider the possibility of a de re construal, which, as I have already pointed out, is relatively marked; (26) may be rendered acceptable, too, if a de re construal is salient). However, (73) is judged to be false in the context in (70), whereas (74) is judged to be true. The data are suggestive of the fact that in Kutchi Gujarati, null pronouns can have a de se reading, whereas overt pronouns cannot.

(73) Khali Valji maan-e ke i jeet-se.

only Valji believe-3.SG.PRES that he win-FUT.3.SG

(GRAMMATICAL AND FALSE)

$\Rightarrow$ overt pronoun cannot have a de se LF

(74) Khali Valji maan-e ke (pro) jeet-se.

only Valji believe-3.SG.PRES that pro win-FUT.3.SG

(GRAMMATICAL AND TRUE) $\quad \Rightarrow$ null pro can have a de se LF

\subsubsection{Kutchi Gujarati part II: null pronouns must be read de se}

I now proceed to show that null pronouns also seem to require a de se reading. It is possible to construct a similar context-sentence pair, in which only the de re reading would be true, and the de se reading would be false. This is given in (75) and (76). In (75), the sentence in (76) would clearly be false in a de se reading (since not every man consciously has a de se belief about himself), cf. (77b). Nevertheless, (76) would be true in a reading without ('de se') self-attribution (since every man has a belief about himself, even if Khimji and Raj do not know it), cf. (77a).

(75) Context: A group of drunk election candidates watching campaign speeches on television do not recognize themselves in the broadcast. Valji and Lalji, the two confident ones, think "I'll win," but do not recognize themselves in the broadcast. Khimji and Raj, both depressive, think "I'll lose" but are impressed by the speeches that happen to be their own and are sure "that candidate" will win.

(76) "Every man believes that he will win."

(77) Summary of facts in (75):

a. people who believe that they themselves will win $=\{$ Valji, Lalji, Khimji, Raj $\}$

b. people who believe de se that they themselves will win $=\{$ Valji, Lalji $\}$

In the parallel Kutchi Gujarati example, we observe that (78) (with the overt pronoun $i$ 'he') is judged to be true. By contrast, (79) (with the null pronoun) is judged to be false, indicating that null pronouns in such contexts must have a de se LF, whereas overt pronouns have a de re LF. Based on the Kutchi Gujarati data in (73)-(74) and (78)-(79), we can tentatively conclude that null pro must have a de se construal (which follows from (74) and (79)), while overt pronouns 
cannot (which follows from (73) and (78)). The Kutchi Gujarati data seem to confirm the prediction outlined above that de se pronouns must be weak. The generalization that strong pronouns cannot be interpreted de se derives straight forwardly, if $d e$ se pronouns must be uninterpreted, and thus cannot contain the 'surplus' structure that stronger pronouns contain. If, on the other hand, de se were a special case of $d e$ re, it would be unclear how this pattern could be derived.

(78) Harek manas maan-e ke i jeet-se.

every man believe-3.SG.PRES that he win-FUT.3.SG

(GRAMMATICAL AND TRUE) $\quad \Rightarrow i$ allows for non-de se belief about oneself

(79) Harek manas maan-e ke (pro) jeet-se.

every man believe-3.SG.PRES that pro win-FUT.3.SG

(GRAMMATICAL AND FALSE) $\quad \Rightarrow$ null pro must be construed de se

Since Kutchi Gujarati does not have demonstrative pronouns of the German/Portuguese type, or clitic pronouns, it is not self-evident how much structure a null pronoun contains, and how it contrasts with an overt pronoun; however, we can at least conclude, once again, that overt pronouns must contain some additional material that null pronouns lack, in the spirit of (29).

\subsubsection{Austrian Bavarian: demonstrative pronouns resist a de se construal}

Let us now turn to belief reports in Austrian Bavarian. Using the Percus \& Sauerland (2003a,b) context from above, we initially observe that the judgments are not as clear-cut as in Kutchi Gujarati. Recall that, given the context in (80), the sentence in (81) should be true in the de se reading, but false in a non-de se reading. We can disregard demonstrative pronouns from now on, since in (81), dea is simply ungrammatical (with reference to Sepp), as predicted by Wiltschko (1998) (see also Hinterwimmer 2015). Looking at personal pronouns, the intuition is that (81) is judged true with the clitic pronoun $a$ 'he', as predicted. However, (81) is also judged true with the strong pronoun $e a$ 'he', which is not what we predicted. ${ }^{14}$ It is unclear at this point why this is the case, but this is a larger question that requires an in-depth understanding of the pronominal system in Bavarian. What we have seen in section 3.2 is that we still observe a correlation of de $s e$ vs. de re interpretation with the choice between clitic vs. non-clitic pronouns in dream reports, even though it is missing in belief reports. Similarly, this distinction can be observed in Kutchi Gujarati belief reports, as shown in 3.3.1-3.3.2. It is thus a question for future research why exactly Bavarian behaves differently with regards to contexts such as (80).

(80) Context: Drunk election candidates are watching campaign speeches on TV, and do not recognize themselves in the broadcast. Sepp, the only confident one, thinks "I'll win," but does not recognize himself in the broadcast. Hias and Rudi, both depressive, think "I'll

\footnotetext{
${ }^{14}$ An anonymous reviewer points out that, once again, (81) may require focus on the strong pronoun, which looks like a potential confound. This confound has already been flagged by Cardinaletti \& Starke (1999:161-162) in the context of their pronominal typology; they reject focus as a relevant factor. For present purposes it should suffice to point out that subject $e a$ 'he' intuitively tends to attract focus more than object eam 'him'. The following example is judged on a par with (81) even if eam is distressed and the default sentential stress is on wöhn 'elect', as indicated.

i. Nua da Sepp glaubt, \{das's'n / das's eam WÖHN wean.

only the Sepp believes that $=$ they $_{C L}=$ him $_{C L}$ that $=$ they ${ }_{C L}$ him elect will

'Only Sepp believes that they will elect him.'
} 
lose" but are impressed by the speeches that happen to be their own and are sure "that candidate" will win. Peter, also depressive, happens to be impressed not by his own speech but by Sepp's.

(adapted from Percus \& Sauerland 2003a)

(81) Nua da Sepp glaubt, $\{$ das'a / das ea $/ *$ das dea $\}$ gwöht wiad.
only the Sepp believes that $=$ he $_{C L}$ that he that DEM elected is
'Only Sepp believes that he will be elected.'

\subsubsection{Interim summary}

Looking at belief reports in Kutchi Gujarati (sections 3.3.1-3.3.2), we have found that strong pronouns once again exhibit a de re preference and weak pronouns a de se preference. This may further corroborate the idea that de se pronouns are uninterpreted, supporting a view such as Percus \& Sauerland $(2003 a, b)$. Note, however, that we have observed a contrast between beliefreports (where strong pronouns appear to allow for de se readings in certain cases, as in (81)) and dream-reports (where strong pronouns generally disallow de se readings) in Bavarian. This brings us back to the question of whether dream reports and belief reports behave on a par when it comes to the observed patterns. In fact, the observation in (81) is in line with the conjecture of Anand (2006), discussed in Pearson \& Dery (2014), that belief reports (but not dream reports) may systematically give rise to de se readings that are derived from de re pronouns without pronoun movement, whereas dream reports may require an uninterpreted de se pronoun, giving rise to a de se LF in the sense of Percus \& Sauerland (2003a,b). (This is much in line with the more recent discussion in Pearson 2018.) The residual question would then be why Kutchi Gujarati still exhibits the pattern in 3.3.1-3.3.2. In any case, while belief reports need to be investigated in more detail, we can conclude that the Percus \& Sauerland (2003a,b) approach is strongly supported by the empirical patterns in dream reports.

\section{Further implications}

In this paper, I have shown that, overall, the Austrian Bavarian and Kutchi Gujarati data support the Percus \& Sauerland (2003a,b) view, which posits uninterpreted de se pronouns that undergo movement to the clausal left periphery. Uninterpreted (dummy) pronouns must be weak, since a strong variant is ruled out, both by the need to be semantically vacuous and by structural economy constraints (Minimize DP!); see Cardinaletti \& Starke (1999:156). We can now turn to further implications of my findings, both with regards to binding theoretic facts in attitude reports, and with regards to potential tests for dedicated de se LFs.

\subsection{Revisiting binding theoretic facts}

I now proceed to present additional data that are consistent with a pronoun movement approach to de se interpretations. Specifically, I show that data from Bavarian confirm the predictions from Percus \& Sauerland (2003a,b) concerning binding theory (as was already foreshadowed in the preceding section). Having argued in favour of dedicated de se LFs, one of the arguments against dedicated de se LFs that has been discussed, e.g. by Santorio (2014), stems from binding theory and is originally due to Heim (1994). To illustrate, Santorio (2014) presents the following scenario (from Sharvit 2011). The puzzling observation is the following. In the scenario in (82), (83a) is acceptable, whereas (83b) is unacceptable. From the perspective of Percus \& Sauerland 
(2003a,b), this seems to give rise to paradoxical conclusions, as we will see momentarily. To see this, consider example (84), which is an adaptation of (83) that is parallel to the examples that we discussed above.

(82) Sarah Palin, who is running for president, wakes up from a coma and suffers from severe memory loss ... McCain visits her in the hospital, and she says to him: 'I don't know who to vote for'. While the two of them look at a picture of her in the newspaper, he says to her: 'You must vote for this woman.' Palin, who does not recognize herself in the picture, says: 'You are right; I will vote for this woman. She seems reliable.'

(Sharvit 2011:56, as quoted in Santorio 2014)

To mirror (83a-b), and reflect the context in (82), she in (84a-b) must be read de se, while herself/her must be read de re. This is indicated by a subscripted de-se / de-re. Given that the judgments in (83) carry over to (84), the example in (84a) is acceptable (on a par with (83a)) and $(84 b)$ is unacceptable (on a par with (83b)). (It is worth pointing out that both (83a) and (84a) are de $s e+$ de re configurations and should thus satisfy superiority.)

(83) a. McCain convinced Palin to vote for herself.

b.* McCain convinced Palin to vote for her.

(quoted from Santorio 2014)

(84) a. Palin believes that $\mathbf{s h e}_{\text {de-se }}$ should vote for herself $\mathbf{f}_{\text {de-re. }}$

b.(\#) Palin believes that $\mathbf{s h e}_{\text {de-se }}$ should vote for $\mathbf{h e r}_{\text {de-re. }}$

The apparent problem can be stated as follows. The standard interpretation of binding theory (cf. Büring 2005 for an overview) is that reflexive pronouns (herself) must have a local antecedent that they are referentially dependent on, whereas non-reflexive pronouns (her) must not have a local antecedent. Example (85b) shows that, at first sight, there does not seem to be a meaningful way in which herself could be referentially dependent on she in (85a) if we assume the Percus \& Sauerland (2003b) analysis. First of all, she and herself cannot be coindexed since she would be an uninterpreted pronoun (as indicated by the asterisk) whereas herself would receive a de re construal; moreover, if herself were coindexed with the trace of the uninterpreted pronoun she, then both pronouns would be construed de se, which is not the intended reading; in other words, herself cannot be locally bound by she. The criticism is thus that a Percus \& Sauerland (2003a,b) analysis predicts (84b) to be grammatical and (84a) to be ungrammatical (since her/herself would not be locally bound by she); this is the opposite of what we find. This criticism targets Percus \& Sauerland's approach in English.

de-se + de-re reading

a. ${ }^{\mathrm{OK}}$ Palin believes that $\mathbf{s h e}_{\mathrm{de}-\mathrm{se}}\left(=\right.$ Palin) should vote for $\left[\right.$ herself $_{\text {de-re }}(=$ the woman on the picture, who happens to be Palin)].

b. LF: Palin 2 believes [CP $\mathbf{s h e}^{*} \lambda \mathbf{x}_{\mathbf{1}}\left[\mathbf{t}_{\mathbf{1}}\right.$ should vote for herself $\left.\left.\mathbf{f}_{\text {(de-re) }}\right]\right]$.

I now proceed to show that languages with strong/weak distinctions in their pronominal paradigm actually pattern on a par with the predictions of Percus \& Sauerland, i.e. whenever we 
have a combination of a de se pronoun and a de re pronoun, we get two non-reflexive pronouns, (84b). We only find a reflexive pronoun, (84a), when a de se + de se reading or a de re + de re reading is intended, which is exactly what we would expect from a Percus \& Sauerland (2003a,b) style approach.

Reconsider the intuitions from Heim (1994), Sharvit (2011) and Santorio (2014), given in (86) (based on the scenario/context in (82)). The idea is that (86a) involves a reflexive de re pronoun, even though there is no suitable local antecedent, assuming that de re pronouns cannot be referentially dependent on de se pronouns.

(86) a. Palin believes that $\mathbf{s h e}_{\text {de-se }}$ should vote for herself $\mathbf{f}_{\text {de-re. }}$

b.(\#) Palin believes that $\mathbf{s h e}_{\text {de-se }}$ should vote for her $_{\text {de-re. }}$

Crucially, we have already seen in section 3.2.2 that the pattern in (86) is not the pattern that we find in Kutchi Gujarati and Bavarian: as shown in (67) for Bavarian (repeated in (87)) and in (68) for Kutchi Gujarati, both pronouns must be non-reflexive in the de se + de re reading and in the de $r e+d e$ se reading. In particular, the acceptable example in (87b) is parallel to the unacceptable English example in (86b).

(87) a. Da Joker håt traamt, das'a da Batman is. the joker has dreamed that $=$ he $_{\mathrm{CL}}$ the Batman am

'The Joker dreamed that he was Batman.' [de se Batman, de re the Joker]

b. Und ea håt traamt, das'a eam übafåin håt. [de se subject/de re object] and he has dreamed that $=\mathrm{I}_{\mathrm{CL}}$ me $\mathrm{FULL}_{\mathrm{F}}$ ambushed has

'And he dreamed that $\mathbf{h e}_{\mathrm{CL}}\left(=\right.$ Batman $\left._{\text {de se }}\right)$ ambushed him FuLL $\left(=\right.$ the Joker $\left._{\text {de re }}\right)$.'

c. Und ea håt traamt, das'n ea übafåin håt. [de re subject/de se object] and he has dreamed that $=$ him $_{\mathrm{CL}}$ he $_{\mathrm{FULL}}$ ambushed has

'And he dreamed that he FULL $_{(=}$the $\left.\operatorname{Joker}_{\text {de re }}\right)$ ambushed him $\mathbf{C L}\left(=\operatorname{Batman}_{\mathrm{de} \mathrm{se}}\right)$.'

By contrast, reflexive pronouns invariably seem to give rise to a reflexive de se + de se or de re + de re interpretation, in (88b) and (88c), which are both somewhat deviant for pragmatic reasons, since it is unlikely that someone would ambush himself. The fact that examples with reflexives, such as $(88 \mathrm{~b}-\mathrm{c})$, require de se + de se or de re + de re readings is striking, since the configuration is parallel to (86a) in English.

(88) a. Da Joker håt traamt, das'a da Batman is. the joker has dreamed that $=\mathrm{he}_{\mathrm{CL}}$ the Batman am

'The Joker dreamed that he was Batman.' [de se Batman, de re the Joker]

b.?? Und ea håt traamt, das'a si übafåin håt. [de se subject/de se object] and he has dreamed that $=\mathrm{I}_{\mathrm{CL}}$ self ambushed has

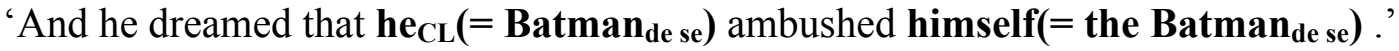

c. ?? Und ea håt traamt, das ea si übafåin håt. [de re subject/de re object]

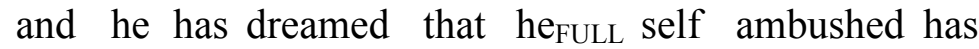

'And he dreamed that he $\mathbf{F U L L}_{\text {( }}\left(=\right.$ the Joker $\left._{\text {de re }}\right)$ ambushed himself(= the Joker $_{\text {de re }}$.' 
From the perspective of Percus \& Sauerland (2003a,b), the Bavarian patterns (and the corresponding Kutchi Gujarati patterns, which are identical), are exactly what we predict, as witnessed by (85). These data are clearly compatible with a view in which distinct de se LFs are generated by movement of an uninterpreted pronoun. Of course, they are also compatible with alternative approaches if we assume that reflexives have a detransitivizing effect on the predicate (turning a transitive VP event into a reflexive VP event of, say, self-ambushing in (88)), ${ }^{15}$ but since this is orthogonal to the present discussion, I will not pursue it further at this point.

Naturally, the insights from Bavarian and Kutchi Gujarati do not shed light on the question of why the English intuitions in (86a-b) come about to begin with; this issue goes beyond the scope of this paper, but it is worth pointing out that we may be forced to conclude that the available or preferred route to de se (i.e., whether a given construction in a given language utilizes dedicated de se LFs or not) may vary, and English simply uses a strategy that is different from the Bavarian / Kutchi Gujarati one. (Such an idea has been corroborated by the results of Pearson \& Dery 2014 within English, who find that Percus \& Sauerland's predictions only follow through with dream, but not with believe).

\subsection{Testing for possible de se LFs}

Looking beyond the scope of this paper, one question that remains largely unanswered concerns the range of attitude predicates that select de se LFs, and how this selection is implemented. Specifically, we have seen that believe takes a clausal complement that denotes a property, repeated in (89), i.e. it quantifies over world/individual pairs, so-called centered worlds; in other words, believe comes equipped with the necessary semantics in order to combine with a complement clause that contains a de se pronoun. By contrast, it has been argued in Percus \& Sauerland (2003a) and Pearson (2012) that there is also a non-de-se variant of believe that only combines with de re LFs (i.e. believe may be ambiguous between believe $e_{\text {ese }}$ and believe de re).

$$
\begin{aligned}
& {[[\text { believe }]]^{\mathrm{g}}=\lambda \mathrm{P}_{<\mathrm{e},<\mathrm{s}, \mathrm{t}>>} \cdot \lambda \mathrm{x} . \lambda \mathrm{w} . \text { For all }<\mathrm{y}, \mathrm{w}^{\prime}>\text { in } \mathrm{DOX}_{\mathrm{x}, \mathrm{w}}, \mathrm{P}(\mathrm{y})(\mathrm{w} ')=1} \\
& \text { where DOX } X_{x, w} \text { stands for the set of pairs }<y, w^{\prime}>\text { such that w' is a world compatible } \\
& \text { with } x \text { 's beliefs in } w \text {, and } y \text { is the individual in w' who } x \text {, in } w \text {, identifies as himself. } \\
& \text { (based on Percus \& Sauerland's } 2003 \mathrm{~b} \text { entry for dream) }
\end{aligned}
$$

In this regard, as pointed out above, Pearson \& Dery (2014) suggest that there may be a difference between dream and believe in terms of whether they select dedicated de se LFs or not. Their experiments indicate that, in English, dream selects dedicated de se LFs, whereas believe does not. They conclude that this may be a contrast where we witness two routes to de se: in the case of English believe, de se readings always come about as a special type of de re reading (see section 2.2); in the case of English dream, de se readings are generally due to dedicated de se LFs (see also Pearson 2018). The generalization from Kutchi Gujarati can now be used to test for dedicated de se LFs in the language. Consider the following example. Patel-Grosz $(2014,2015)$ argues that epithets are anti-de-se pronouns, i.e. a type of pronominal element that cannot be construed de se. A puzzling observation in this respect is the contrast between (90a) and (90b); an epithet that refers to the current attitude holder is unacceptable in the complement of knows, (90a), but acceptable in the complement of doesn't know, (90b). These data seem to indicate that a complement clause of knows must have a de se LF, (91a), whereas the complement clause of doesn't know must have a de re LF, (91b).

\footnotetext{
${ }^{15}$ I am grateful to an anonymous reviewer for pointing this out.
} 
(90) a. * Nero 1 knows that the damn traitor ${ }_{1}$ should invite Sarkozy to the peace talks.

b. ${ }^{\text {?OK }}$ Nero $_{1}$ doesn't know that the damn traitor ${ }_{1}$ should invite Sarkozy to the peace talks.

(91) a. Nero 1 knows [de se LF that the damn traitor $_{1}$ should invite Sarkozy]. * epithet

b. Nero, doesn't know [de re LF that the damn traitor ${ }_{1}$ should invite Sarkozy]. OK epithet

This contrast indicates that the ability of a predicate to select a de se LF may interact compositionally with phenomena such as, say, clausal negation - an interaction that is not yet fully understood. However, if this reflects a more general fact about complements of know vs. not know, then we expect to find the following in Kutchi Gujarati.

We have established for Kutchi Gujarati that null pro correlates with a de se construal (section 3.3.2), whereas overt $i$ 'he' correlates with a de re construal (section 3.3.1). We can use this generalization as a diagnostic for whether a given predicate selects a de se LF or not. Consider the data in (92). In (92a), the null pro must refer to Valji and it is construed de se, whereas an overt $i$ 'he' must refer to someone else (unless a de re context is construed, which is rather difficult in this case); contrastively, in (92b), overt $i$ 'he' can refer to Valji and null pro seems to be ungrammatical. If overt $i$ 'he' has to be read de re, this indicates that a self-directed (i.e. de se) lack of knowledge in (92b) cannot be due to a dedicated de se LF; (92b) must be a case where de se arises as a special case of de re (see also sections 2.2 and 3.3.4).

(92) a. Valji $\mathbf{1}_{1}$-ne khabare ke $\left\{\right.$ pro $\left._{1} / \mathrm{i}_{* 1}\right\}$ kotu karyu.

Valji-DAT knows that pro he wrong did

'Valji knows that he did wrong.'

b. Valji $1_{1}$-ne khabar nathi ke $\left\{\mathbf{i}_{1} /{ }^{*}\right.$ pro $\}$ kotu karyu. Valji-DAT know not.is that he pro wrong did

'Valji does not know that he did wrong.'

The generalization that emerges is summarized schematically in (93). As shown in (93a), khabare 'knows' seems to require a complement clause with a de se LF. By contrast, khabar nathi 'does not know' in (93b) fails to select for a complement clause with a de se LF. Presumably, (93b) then involves a de re LF that emulates a de se reading. The question arises why (93a) does not allow for such a de re LF, i.e. why is a route of deriving de se as a special use of de re blocked in (93a)?

(93) a. Valji $\mathbf{1}_{1}$-ne khabare [de se LF/*de re LF ke pro p $_{1}$ kotu karyu]. only null pro Valji-DAT knows that pro wrong did

b. Valji $\mathbf{1}_{\text {-ne }}$ khabar nathi [*dese LF/de re LF ke $\mathbf{i}_{\mathbf{1}}$ kotu karyu]. onlyovert pronoun Valji-DAT know not.is that he wrong did

In the spirit of Schlenker's (2005a) we can argue that (93b) lacks a de se LF to begin with, but in (93a) both a de se LF and a de re LF are possible. Subsequently, the de re LF in (93a) is blocked due to Schlenker's constraint Prefer De Se!, as quoted in (94).

(94) Prefer De Se! (Schlenker 2005a:292)

Whenever this is compatible with the situation which is reported, prefer a De Se over a De Re Logical Form. 
Alternatively, one could pursue the type of pragmatic reasoning outlined in section 3.2.1, where we faced a similar challenge in the step from (52), where weak pronouns are expected to be ambiguous between a de se reading and a de re reading, to (54), where weak pronouns are understood to be unambiguously de se. The (52)-to-(54) conundrum is much in line with the challenge posed by (93a).

Of course, the discussion of (92) assumes that there is a one-to-one correspondence between null pronouns under attitude predicates and dedicated de se LFs (and between overt pronouns and a de re construal). This is plausibly a simplification, given the discussion throughout section 3 . However, I hope to have shown that the Kutchi Gujarati data indicate that know selects for a de se LF, whereas not know does not seem to select for a de se LF. It is still an open question how to account for this contrast, but a possible approach could be built on the idea that knowing and not knowing clearly differ in what they entail; for instance, if know selects a de se LF, this may indicate that the attitude holder has a justified true belief that is consciously self-directed. What would it mean for not know to select a de se LF? This would plausibly mean that the attitude holder lacks a justified true belief that is consciously self-directed. One explanation for the lack of a de se LF under not know may be that such a configuration is simply conceptually deviant. Future research needs to determine whether there is independent support for such an idea.

\section{Conclusion}

In this paper, I raised the question of how the de se / de re distinction interfaces with the (morpho-)syntax of the expressions that are involved. I developed a novel hypothesis at the morphosyntax-semantics interface, arguing that the semantics of pronouns in attitude contexts is strongly interlinked with their internal (morpho-)syntactic structure, i.e., with the amount of functional material that they project.

My empirical focus was on evidence from Kutchi Gujarati and (Austrian) Bavarian; in these languages, 'weakness' of pronominal form (which I assume to reflect a lack of internal structure) correlates with the possibility (or even necessity) of a de se reading. On the theory side of this paper, I argued, in particular, that the preference for de se pronouns to be 'weak' follows naturally if we assume constructions with dedicated de se LFs, where de se pronouns are semantically uninterpreted (i.e., vacuous) and merely trigger predicate abstraction. Stronger pronouns either contain semantically interpretable material, which trivially blocks them from being uninterpreted, or they are blocked by structural economy constraints (specifically by a Minimize DP! constraint that has independently been established).

I contrasted such a view, which assumes dedicated de se LFs, with a view that does not. In doing so, I argued that the correlations that I observe do not follow as straightforwardly if de se pronouns and de re pronouns are always completely equivalent in their semantic interpretation (which may be taken to be the default implication of a view where de se is always a special case of $d e r e$ ). The reasoning is that this would also imply a parallel internal (i.e., morphosyntactic) structure. Therefore, I argued that my findings support a view in which at least some de se pronouns are morphosyntactically (and semantically) distinct from regular (de re) pronouns; this, in turn, follows naturally from an approach that assumes dedicated LFs for de se interpretations. 


\section{References}

Anand, Pranav (2006). De De Se. PhD dissertation, MIT.

Bosch, Peter, \& Carla Umbach (2007). Reference Determination for Demonstrative Pronouns, in Dagmar Bittner \& Natalia Gargarina (eds.): Intersentential Pronominal Reference in Child and Adult Language, ZAS Papers in Linguistics 48, 39-51.

Bosch, Peter, Tom Rozario, and Yufan Zhao. 2003. Demonstrative Pronouns and Personal Pronouns. German der vs. er. In Proceedings of the EACL2003.

Cardinaletti, Anna \& Michal Starke (1999). The typology of structural deficiency: A case study of the three clases of pronouns. In H. van Riemsdijk (ed.): Clitics in the languages of Europe. Berlin: de Gruyter, 145-233.

Chierchia, Gennaro (1989). Anaphora and Attitudes De Se. In R. Bartsch, J. van Benthem, and van Emde Boas (eds.): Semantics and Contextual Expression. Dordrecht: Foris, 1-32.

Chomsky, Noam (1973). Conditions on transformations. In S.R. Anderson \& P. Kiparsky (eds.): A festschrift for Morris Halle. New York: Holt, Rinehart and Winston.

Chomsky, Noam (1981). Lectures on Government and Binding. Dordrecht: Foris.

Chomsky, Noam (1995). The Minimalist Program. Cambridge, MA: MIT Press.

Déchaine, Rose-Marie, and Martina Wiltschko. 2002. Decomposing Pronouns, Linguistic Inquiry 33, 409-442.

Grewendorf, Günther (1988). Aspekte der deutschen Syntax. Eine Rektions- und Bindungsanalyse. Tübingen: Narr.

Heim, Irene, and Angelika Kratzer (1998). Semantics in Generative Grammar. Oxford: Blackwell.

Heim, Irene (1994). Puzzling Reflexive Pronouns in De Se Reports. Unpublished handout, MIT.

Hinterwimmer, Stefan (2015). A unified account of the properties of German demonstrative pronouns. In Patrick Grosz, Pritty Patel-Grosz, and Igor Yanovich (eds.): NELS 40: Semantics Workshop on Pronouns. Amherst: University of Massachusetts, Graduate Linguistic Student Association, 61-107.

Ihsane, T., and G. Puskas (2001). Specific is Not Definite, $G G @ G$, vol. 2. University of Geneva, 39-54.

Kaplan, David (1968). Quantifying In. Synthèse 19, 178-214.

Katzir, Roni. 2011. Morphosemantic Mismatches, Structural Economy, and Licensing. Linguistic Inquiry 42, 45-82.

Krifka, Manfred (2008). Basic Notions of Information Structure, Acta Linguistica Hungarica 55, 243-276.

Laenzlinger, Christopher (2005). French adjective ordering: perspectives on DP internal movement types. Lingua 115, 645-689.

Lewis, David K. (1979). Attitudes De Dicto and De Se. Philosophical Review 88, 513-43.

Maier, Emar (2011). De Se reports revisited. Manuscript, University of Groningen.

Patel-Grosz, Pritty (2014). Epithets as de re pronouns. Empirical Issues in Syntax \& Semantics 10,91-106.

Patel-Grosz, Pritty (2015). Epithets at the Syntax-Semantics Interface. Newcastle: Cambridge Scholars Publishing.

Patel-Grosz, Pritty and Patrick Grosz (2010). On the Typology of Donkeys: Two Types of Anaphora Resolution. Proceedings of Sinn und Bedeutung 14, 339-355.

Patel-Grosz, Pritty, and Patrick Grosz (2017). Revisiting pronominal typology. Linguistic Inquiry 48, 259-297. 
Pearson, Hazel (2012). The Sense of Self: Topics in the Semantics of De Se Expressions. PhD dissertation, Harvard University.

Pearson, Hazel \& Jeruen Dery. 2014. Dreaming de re and de se: Experimental evidence for the Oneiric Reference Constraint. In Proceedings of Sinn und Bedeutung 18, 322-339.

Pearson, Hazel (2015). The interpretation of the logophoric pronoun in Ewe. Natural Language Semantics 23, 77-118.

Pearson, Hazel (2018). Counterfactual de se. Semantics and Pragmatics 11(2). [Early access version.]

Percus, Orin \& Uli Sauerland (2003a). On the LFs of Attitude Reports. In Proceedings of Sinn and Bedeutung 7, 228-242.

Percus, Orin \& Uli Sauerland (2003b). Pronoun Movement in Dream Reports. In Proceedings of NELS 33, 265-283.

Perry, J. (1979). The problem of the essential indexical. Nous 13, 3-21.

Reinhart, T. (1983). Anaphora and Semantic Interpretation. Chicago: University of Chicago Press.

Reinhart, T. (1990). Self-representation. Unpublished manuscript.

Reinhart, T. (1995): Interface Strategies. Technical Report OTS Working Papers, Utrecht University.

Rooth, Mats. 1985. Association with Focus. Doctoral dissertation, University of Massachusetts, Amherst.

Rooth, Mats. 1992. A Theory of Focus Interpretation. Natural Language Semantics 1, 75-116.

Santorio, Paolo (2014). On the Plurality of Indices. Manuscript, University of Leeds.

Schlenker, P. (2003). A plea for monsters. Linguistics and Philosophy 26, 29-120.

Schlenker, Philippe (2005a). The Lazy Frenchman's Approach to the Subjunctive. In I. v. G. T. Geerts, and H. Jacobs (eds.): Romance Languages and Linguistic Theory. Benjamins: Oxford, 269-309.

Schlenker, Philippe. 2005b. Minimize Restrictors! (Notes on Definite Descriptions, Condition C and Epithets), in Proceedings of SuB 9, 385-416.

Schwarz, Florian. 2009. Two Types of Definites in Natural Language. Ph.D. thesis, University of Massachusetts Amherst.

Sharvit, Yael. 2011. Covaluation and unexpected BT effects. Journal of Semantics 28.

Weiß, Helmut. 1998. Syntax des Bairischen. Studien zur Grammatik einer natürlichen Sprache. Tübingen: Niemeyer.

Wiltschko, Martina. 1997. D-Linking, Scrambling and Superiority in German. Groninger Arbeiten zur Germanistischen Linguistik 41, 107-142.

Wiltschko, Martina. 1998. On the Syntax and Semantics of (Relative) Pronouns and Determiners, Journal of Comparative Germanic Linguistics 2, 143-181. 